\title{
Using mechanical experiments to study ground stone tool use: Exploring the formation of percussive and grinding wear traces on limestone tools
}

\author{
Eduardo Paixão a,b,e,* , Antonella Pedergnana ${ }^{\text {a }}$, João Marreiros ${ }^{\text {a,b,e }}$, Laure Dubreuil ${ }^{\text {c }}$, \\ Marion Prévost ${ }^{\mathrm{d}}$, Yossi Zaidner ${ }^{\mathrm{d}}$, Geoff Carver ${ }^{\mathrm{a}}$, Walter Gneisinger ${ }^{\mathrm{a}}$ \\ ${ }^{a}$ Laboratory for Traceology and Controlled Experiments (TraCEr), MONREPOS - Archaeological Research Centre and Museum for Human Behavioural Evolution, \\ RGZM, Germany \\ ${ }^{\mathrm{b}}$ ICArEHB - Interdisciplinary Center for Archaeology and Evolution of Human Behaviour, Universidade do Algarve, Portugal \\ ${ }^{\mathrm{c}}$ Department of Anthropology, Trent University, Canada \\ ${ }^{\mathrm{d}}$ The Institute of Archaeology, Hebrew University of Jerusalem, Israel \\ ${ }^{\mathrm{e}}$ Institute for Prehistoric and Protohistoric Archeology, Johannes Gutenberg University, Mainz, Germany
}

\section{A R T I C L E I N F O}

\section{Keywords:}

Ground stone tools

Use-wear

Experiments

Quantitative artifact microwear analysis

3D scanning

Levant

Paleolithic

\begin{abstract}
A B S T R A C T
Ground Stone Tools (GST) have been identified in several Levantine archaeological sites dating to the Middle Paleolithic. These tools, frequently made of limestone, are often interpreted based on their morphology and damage as having been used for knapping flint, and sometimes for breaking animal bones or processing vegetal materials as well. However, the lack of experimental referential collections on limestone is a major obstacle for the identification of diagnostic traces on these types of tools and raw material. In this sense, the understanding of the specific function of these GST and the association between tool types and activity often remains unknown or merely speculative.

Recent discoveries at the site of Nesher Ramla revealed one of the largest Middle Paleolithic assemblages of limestone GST. Our use-wear analysis has identified several types of both macro and micro-wear traces on different tools. Such diversity highlights the need for developing an experimental reference collection that can enable detailed comparison between experimental and archaeological use-wear evidence.

In this paper, we present the results of mechanical experiments specially designed to understand and quantify major characteristics of macro and micro use-wear traces on limestone GST as a result of three main activities: 1) animal bone breaking, 2) flint knapping and 3) grinding acorns. This study pursues three main goals: a) improving our ability to distinguish natural from anthropogenic alterations on limestone; b) identifying and characterizing differences between wear-traces (macro and micro) produced by different activities, and c) building a reference collection for thorough comparisons of use-wear and residues on archaeological tools.

Our results indicate that it is possible not only to identify anthropogenic alterations but also to specifically distinguish the use-wear traces formed on limestone as result of percussive activities of bone and flint. This is shown by controlled experiments allowing variables other than the worked material to remain constant.

This study aims to contribute towards establishing an experimental and multi-scale library of use-wear traces on limestone.
\end{abstract}

\section{Introduction}

Ground stone tool (GST) analyses play a major role in archaeological research, providing invaluable data for the reconstruction of past human activities. This tool category traditionally includes artifacts used or manufactured through percussion, pounding, grinding, abrading and/or polishing (Adams, 2014; Dubreuil \& Savage, 2014). GST are of specific interest for studying the evolution of human technologies as they can provide direct evidence for a wide range of daily percussive, pounding or grinding activities. These tools appear in the archaeological record from very early periods to the present day, across a wide geographic distribution (Adams, 2002; Arroyo

\footnotetext{
* Corresponding author at: Laboratory for Traceology and Controlled Experiments (TraCEr), MONREPOS - Archaeological Research Centre and Museum for Human Behavioural Evolution, RGZM, Germany.

E-mail address: paixao@rgzm.de (E. Paixão).
} 

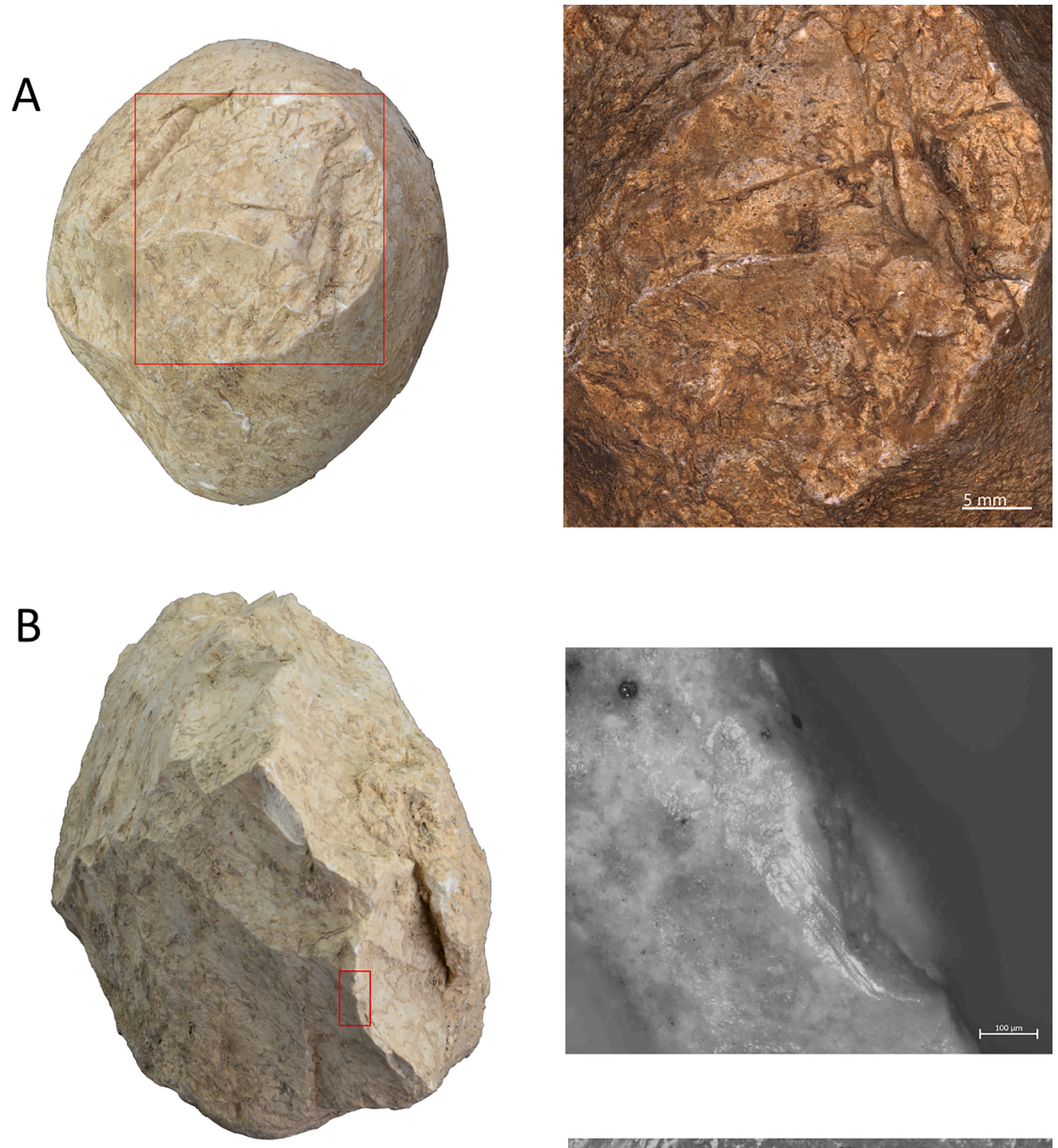

C

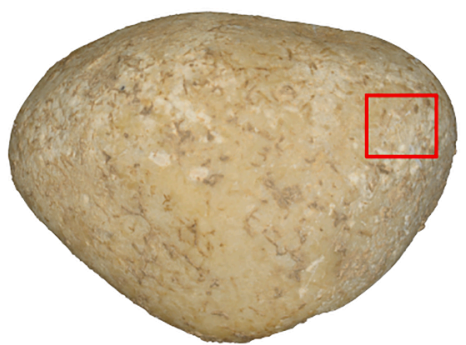

$10 \mathrm{~cm}$

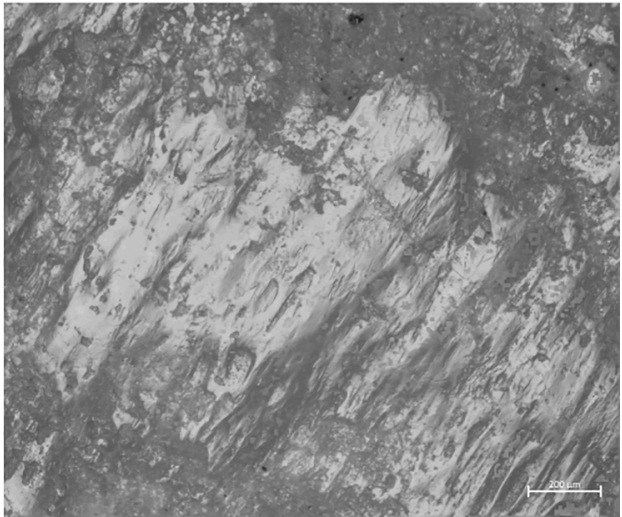

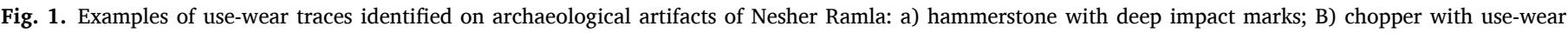
polish; c) hammerstone showing the combination of polish and impact marks.

et al., 2020; Cristiani et al., 2012; de Beaune, 2004; Dubreuil, 2014; Goren-Inbar et al., 2002; Hayes, 2015; Liu et al., 2010; Pop et al., 2018; Rosenberg \& Nadel, 2017; Torre \& Mora, 2010; Valamoti et al., 2013; Wright, 1994). GST use is shared with primates who crack nuts (Boesch and Boesch, 1984; Whiten et al., 2005; Arroyo et al., 2021). In addition, GST are generally well preserved and found in abundance in various archaeological contexts.
Understanding the specific function of these tools has been one of the greatest challenges. For a long time, GST studies have focused mainly on the analysis of the tool morphology (e.g., shape and cross-section of the worked surface). As for other artifacts, GST are frequently assigned to specific type and function based on their shape, or through ethnographic analogies, but not necessarily on direct evidence of having been used for a specific task. This approach can easily lead to misinterpretations of the 
activities represented in the archaeological assemblages, which in turn can impact the way we understand past human behaviour.

A multidisciplinary and multiscale approach that combines detailed raw-materials characterization, techno-typology and use-wear analyses is fundamental to better identifying these tools and for extrapolating hypotheses about their function, a multidisciplinary and multiscale approach that combines detailed raw-materials characterization, techno-typology and use-wear analyses is fundamental (Dubreuil et al., 2015; Marreiros, et al., 2020). Use-wear analysis is a key approach to understanding past tool use in general, but is specifically pivotal for GST studies, as assemblages often include tools used ad-hoc, without prior manufacture (e.g. pebbles or cobbles used as hammerstones), the identification of which depends on our ability to recognise use-wear patterns.

While use-wear formation on GST was explored in the pioneering work of Semenov (1964), further development in this field has been particularly marked by the research carried out by Jenny Adams (1988 and 1989). Adams outlined an analytical framework at low magnifications, and - importantly - referred to the science of tribology to help explain the mechanisms of wear formation (Adams, 2014). Some of the earliest exploration of use-wear on GST also encompassed quantification of surface roughness (through tactile as well as laser rugosimetry) and 3D modelling at various magnifications (Dubreuil, 2002; Procopiou et al., 1998; Procopiou, 2004).

In recent years, several studies have highlighted the potential of 3D approach in GST analysis. Different types of computation based on the terrain analysis of surface digital elevation models (DEM) have brought great improvements, helping to reduce analytical subjectivity by providing quantitative data of surface modification related to use (e.g. Benito-Calvo et al., 2015, 2018; Caricola et al., 2018; Zupancich et al., 2019). By converting digital surfaces into numerical comparative data, these techniques allow very detailed and precise comparisons between tools surfaces, by converting digital surfaces into numerical comparative data. Such detailed comparisons are especially relevant when used as a complementary approach to 'qualitative' descriptions, as they allow thorough characterization as well as corroboration of the observed patterns.

Understanding use-wear formation is highly dependent on the development of experimental collections, which allow traces diagnostic of a contact material(s) and/or activity(s) to be identified (Arroyo \& de la Torre, 2020; de la Torre et al., 2013; Dubreuil et al., 2015; Fullagar et al., 2012; Hayes et al., 2018; Iovita et al., 2014; Marreiros et al., 2020; Pereira et al., 2017). Tool raw material properties (e.g. hardness, roughness, grain size) and the physical properties of the worked materials play a significant role in use-wear formation. Therefore, it is important to develop experimental protocols using raw materials similar to those found in the archaeological sites under study. More generally, experimental protocols should be based on questions, functional hypotheses, and toolkits that are relevant to the context being analysed (Marreiros et al., 2020).

This article focuses on the Levantine Paleolithic archaeological record, where numerous collections of limestone GST have been documented and associated with some of the earliest evidence of settlement in the area. For the Paleolithic period, examples of GST range from the Acheulean (e.g. Gesher Benot Ya'aqov; Goren-Inbar et al., 2002, 2015), where pitted stones were identified and interpreted as tools used in nutcracking activities, to the Late Epipaleolithic, where GST frequencies exponentially increased and a wider range of activities was identified, including the processing of organic and inorganic products (Dubreuil, 2004; Dubreuil and Grosman, 2009; Belfer-Cohen \& Hovers, 2005; Wright, 1994). Between these early manifestations and Later Epipaleolithic development, the transformation of GST technology, the tool types represented and their function(s), have long remained poorly known. In the last decade, however, excavation at various Middle Paleolithic (MP) sites have helped to fill this gap as GST have been identified in several open-air sites, in especially high frequencies at
Table 1

General inventory of all experimental samples.

\begin{tabular}{|c|c|c|c|c|c|}
\hline $\begin{array}{l}\text { Sample } \\
\text { ID }\end{array}$ & $\begin{array}{l}\text { Raw } \\
\text { material }\end{array}$ & $\begin{array}{l}\text { Contact } \\
\text { Material }\end{array}$ & $\begin{array}{l}\text { Type of } \\
\text { movement }\end{array}$ & $\begin{array}{l}\text { Weight } \\
\text { applied } \\
(\mathrm{Kg})\end{array}$ & $\begin{array}{l}\text { Impacts/ } \\
\text { Rotations }\end{array}$ \\
\hline $3-7$ & Limestone & $\begin{array}{l}\text { Fresh } \\
\text { Bone }\end{array}$ & Impact & 2 & 100 \\
\hline $\begin{array}{c}\text { anvil- } \\
\text { flint }\end{array}$ & Limestone & $\begin{array}{l}\text { Fresh } \\
\text { Bone }\end{array}$ & Impact & 2.5 & 900 \\
\hline $\begin{array}{l}\text { anvil- } \\
\text { bone }\end{array}$ & Limestone & Flint & Impact & 2.5 & 970 \\
\hline $3-3$ & Limestone & Flint & Impact & 2.5 & 50 \\
\hline $3-8$ & Limestone & $\begin{array}{l}\text { Fresh } \\
\text { Bone }\end{array}$ & Impact & 2.5 & 50 \\
\hline $2-11$ & Limestone & $\begin{array}{l}\text { Fresh } \\
\text { Bone }\end{array}$ & Impact & 2.5 & 50 \\
\hline 3-11 & Limestone & $\begin{array}{l}\text { Fresh } \\
\text { Bone }\end{array}$ & Impact & 2.5 & 50 \\
\hline $3-1$ & Limestone & $\begin{array}{l}\text { Fresh } \\
\text { Bone }\end{array}$ & Impact & 2.5 & 85 \\
\hline $3-9$ & Limestone & $\begin{array}{l}\text { Fresh } \\
\text { Bone }\end{array}$ & Impact & 2.5 & 50 \\
\hline $3-5$ & Limestone & $\begin{array}{l}\text { Fresh } \\
\text { Bone }\end{array}$ & Impact & 2.5 & 50 \\
\hline $2-6$ & Limestone & $\begin{array}{l}\text { Fresh } \\
\text { Bone }\end{array}$ & Impact & 2.5 & 200 \\
\hline $3-4$ & Limestone & $\begin{array}{l}\text { Fresh } \\
\text { Bone }\end{array}$ & Impact & 2.5 & 50 \\
\hline $3-10$ & Limestone & $\begin{array}{l}\text { Fresh } \\
\text { Bone }\end{array}$ & Impact & 2.5 & 50 \\
\hline $3-6$ & Limestone & $\begin{array}{l}\text { Fresh } \\
\text { Bone }\end{array}$ & Impact & 2.5 & 500 \\
\hline $4-1$ & Limestone & Flint & Impact & 2.5 & 6 \\
\hline $2-12$ & Limestone & Flint & Impact & 2.5 & 50 \\
\hline $2-1$ & Limestone & Flint & Impact & 2.5 & 50 \\
\hline $2-2$ & Limestone & Flint & Impact & 2.5 & 50 \\
\hline $2-9$ & Limestone & Flint & Impact & 2.5 & 50 \\
\hline 3-12 & Limestone & Flint & Impact & 2.5 & 50 \\
\hline $2-10$ & Limestone & Flint & Impact & 2.5 & 7 \\
\hline $2-7$ & Limestone & Flint & Impact & 2.5 & 50 \\
\hline $2-5$ & Limestone & Flint & Impact & 2.5 & 50 \\
\hline $6-5$ & Limestone & $\begin{array}{l}\text { Humid } \\
\text { Acorn }\end{array}$ & circular & 7 & 1000 \\
\hline $6-2$ & Limestone & Dry Acorn & circular & 7 & 1000 \\
\hline 6-1 & Limestone & Dry Acorn & circular & 7 & 1000 \\
\hline $6-6$ & Limestone & Dry Acorn & circular & 7 & 1000 \\
\hline $6-7$ & Limestone & $\begin{array}{l}\text { Humid } \\
\text { Acorn }\end{array}$ & circular & 7 & 1000 \\
\hline $6-3$ & Limestone & $\begin{array}{l}\text { Humid } \\
\text { Acorn }\end{array}$ & circular & 7 & 1000 \\
\hline $6-10$ & Limestone & $\begin{array}{l}\text { Humid } \\
\text { Acorn }\end{array}$ & circular & 7 & 3000 \\
\hline $6-12$ & Limestone & Dry Acorn & circular & 7 & 3000 \\
\hline
\end{tabular}

Nesher Ramla, 170-80 ka BP (Prévost \& Zaidner, 2020; Zaidner et al., 2014, 2018, Paixão et al., Submitted), and in lower frequencies at Ein Qashish, 70-55 ka BP (Been et al., 2017; Ekshtain et al., 2019; Hovers et al., 2008; Malinsky-Buller et al., 2014), Far'ah II, 49-47 ka BP (Gilead \& Grigson, 1984; Goder-Goldberger et al., 2020), Umm El Tlel, ca. 70 BP (Boëda et al., 2008; Griggo et al., 2011) and Quneitra, ca. 55 ka BP (Goren-Inbar, 1990; Oron \& Goren-Inbar, 2014).

The analysis presented in this paper is part of a larger research program aimed at investigating MP GST technology by integrating a multi-approach functional analysis. A significant part of the MP GST mentioned above are made of limestone, and this raw material is especially abundant at Nesher Ramla, the largest assemblage of our archaeological sample (more than a hundred tools in a single layer). Limestone has not been the focus of many experimental programs thus far (Dubreuil et al., 2015). In order to better understand use-wear formation on limestone, we developed experiments centred on three main activities: 1) bone breaking, 2) flint knapping and 3) grinding acorns. While preliminary analysis of the Nesher Ramla collection indicated that 


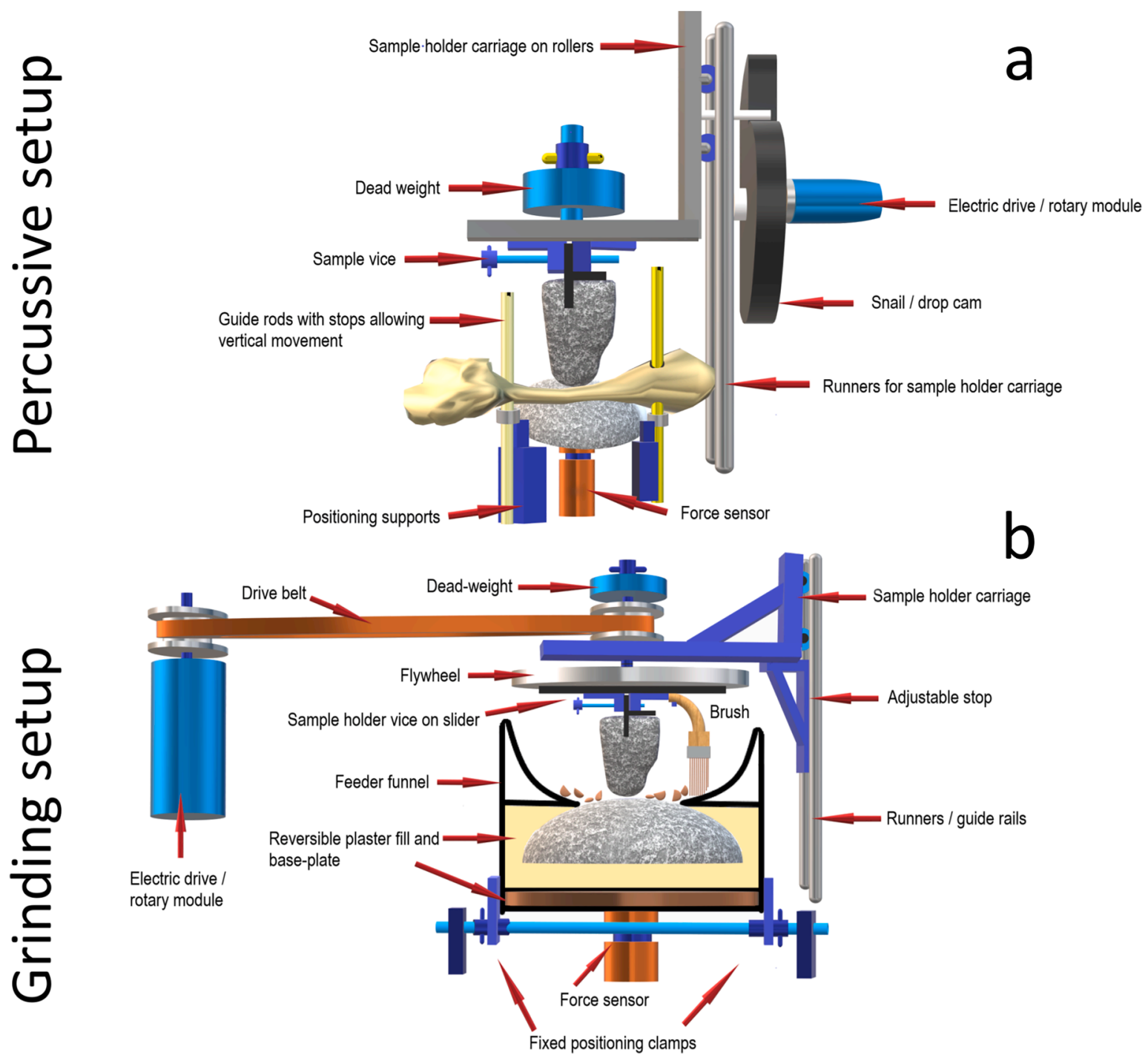

Fig. 2. Experimental mechanical designs: a) Percussive setup; b) Grinding setup (Drawing by Walter Gneisinger).

most of the tools correspond to natural cobbles used in percussion motions against hard matter (likely as hammerstones), some use-wear patterns potentially indicative of abrading/grinding a non-abrasive and greasy matter were also identified (Paixão et al., in press) (Fig. 1). In order to explore this hypothesis, grinding experiments were therefore included. Testing a range of distinct activities is also important in order to be better able to define differences and potential overlap between usewear patterns. The question of bone breakage is especially relevant here because of 1) evidence of bone fragmentation documented at the site (Zaidner et al, 2018; Crater Gershtein et al., 2020) and 2) suggestions of potentially poor development and visibility of wear and/or overlap with use-wear patterns associated with flint knapping (de la Torre et al., 2013; Pop et al., 2018; Benito-Calvo et al., 2018). Probably the most original part of our program is the focus on mechanical experiments specially designed to understand and quantify major characteristics of macro and micro use-wear traces. The potential of such a multi-scale approach for assessing differences and overlap in use-wear patterns is explored in this paper.

\section{Materials and methods}

\subsection{Experimental organization}

In order to establish a reference collection relevant for MP Levantine assemblages - and more particularly for the analysis of Nesher Ramla GST - limestone cobbles were collected from the beds of the Nahal Ayalon river located a few hundred meters away from the site.

To explore the formation of diagnostic use-wear features resulting from the contact with different materials, three products were processed in the experiments: flint, bone (Heck cattle femur bones) and acorns. The bones used were heck cattle femurs in a fresh state while both dry and moist acorns were worked in order to test grinding materials with different physical properties.

The experiments were grouped in two different categories based on the type of motion. Percussive motion was employed for breaking the bones and striking the flint nodules, while the acorns were ground through the application of circular movements (mimicking grinding).

Several variables were measured and controlled during the experiments. For the percussive experiments, the number of impacts, the impact force and the sample position were the dependent variables for the percussive activities, while the only independent variable was the type of worked material (i.e., fresh bone, flint; Table 1). In the case of the grinding experiments, the number of rotations, velocity of rotation, force applied and sample position were the dependent variables for the grinding activity, the only independent variable being the state of the worked material, that consisting of dry and moist acorns (acorns soaked in room temperature tap water for $14 \mathrm{~h}$.

Despite the fact that we used cobbles as similar as possible in terms of 


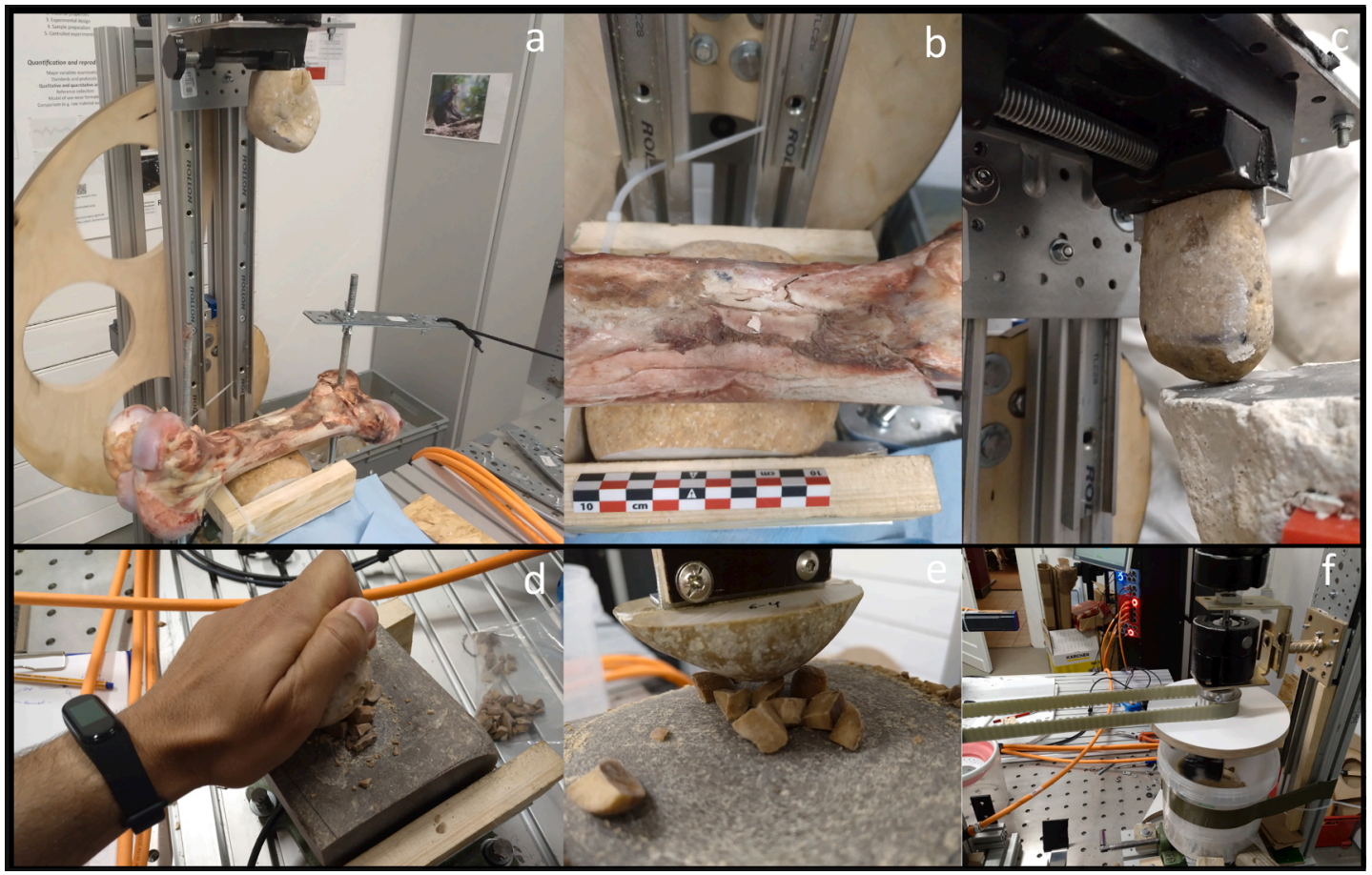

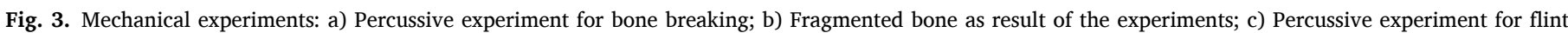
knapping; d) Manual experiments with a force sensor; e) Grinding experiments on dry acorns; f) Grinding experiments on moist acorns.

size and shape, one parameter was very difficult to properly control in this experiment: the morphology of the contact area or active surface of the limestone cobbles. The active area corresponds to the natural cortical surface of the river cobbles, and differs slightly from cobble to cobble.

\subsection{The experimental design}

In order to get a high level of standardization in terms of force, velocity, number of impacts/rotations, and sample position, we used a mechanical device (SMARTTESTER ${ }^{\circledR}$, manufactured by Inotec AP $\mathrm{GmbH}$, with adaptations made by Walter Gneisinger) that allowed us to control and record a number of parameters involved in the experiment (Calandra et al., 2020).

The mechanized percussion experiments were performed by applying a standardized number of impacts, while the previously defined main variables were kept constant throughout the entire duration of the activities. We defined the value of the impact force to be used in the mechanical experiments by running a manual version of the experiment, where a bone was manually battered with a hammerstone and a sensor located under the anvil recorded the impact force of each stroke. This allowed us to define a valid reference for an average value. Then we applied dead weights to our sample holder on the mechanical device until an approximation of the previously observed value $(2.5 \mathrm{Kg})$ was reached, employing further sensor readings (Fig. 2). The force applied during the grinding experiments was set following the same principle; a preceding manual experiment was carried out to record the force of the manual movements through a sensor located under the passive stone.

The SMARTTESTER is a modular test rig primarily developed for industry to assess product durability. This machine is designed to perform standard and consistent movements and registers the activity parameters in a central computer. It allows us to predefine the type of movement (e.g. linear, circular, impact), the number of repeats and to record the force involved in the action by using force sensors. For this experiment we designed and used a percussion and a rotary setup. The setup for percussive motion consists of a modular rotary drive to rotate a snail/drop cam that periodically lifts and drops a sample holder carriage on runners. The percussive tool sample is attached to a vice on the sample holder carriage in a defined position. Weights are added to the sample holder carriage in order to emulate the previously recorded impact force applied to the worked material. A piezoelectric force sensor is located under the dropping point which measures the impacts during the experiment and transmits the readings to a central computer. The rotary setup uses the rotary drive module with an attached circular plate/flywheel, onto which a sample can be attached in different positions (Calandra et al., 2020). Positioning supports are provided to limit any target sample motion to a vertical direction only, allowing for further sensor readings.

For the grinding experiments, the rotary drive module was mounted to rotate a flywheel via a toothed drive belt (Fig. 2). The top stone is fixed in the vice of the sample holder that is attached to the rotating flywheel in order to move the top stone in a circular grinding motion. Dead weights were added in the fashion described above. The sample holder carriage on rollers is limited in its vertical movement by an adjustable stop on the runners to avoid stone-stone contact. The bottom stone was mounted inside a bucket under a funnel where the acorns are deposited for grinding. The acorns are fed towards the centre of the bottom stone with the help of a brush which is attached to the flywheel. The bottom of the bucket was filled with a reversible plaster fill and a base plate in order to create a flat surface for the contact with the force sensor. The bucket itself was held in position, as for the percussive setup, to allow for vertical motion enabling the sensor to generate readings. As before, any sensor readings serve only as internal reference values and should not be quoted out of context or transferred to the design of other mechanical systems. (Fig. 2 and Fig. 3)

\subsection{The experimental samples}

Thirty-one limestone river cobbles were used in our experiments. Twelve samples were used for bone breaking activities, eleven for flint knapping activities, four for grinding dry acorns and four for moist acorns (short videos of the experiments can be found here https://zeno do.org/record/4585367, SOM6) (Table 1). 


\section{Bone breaking (500 impacts) Flint knapping (50 impacts)}

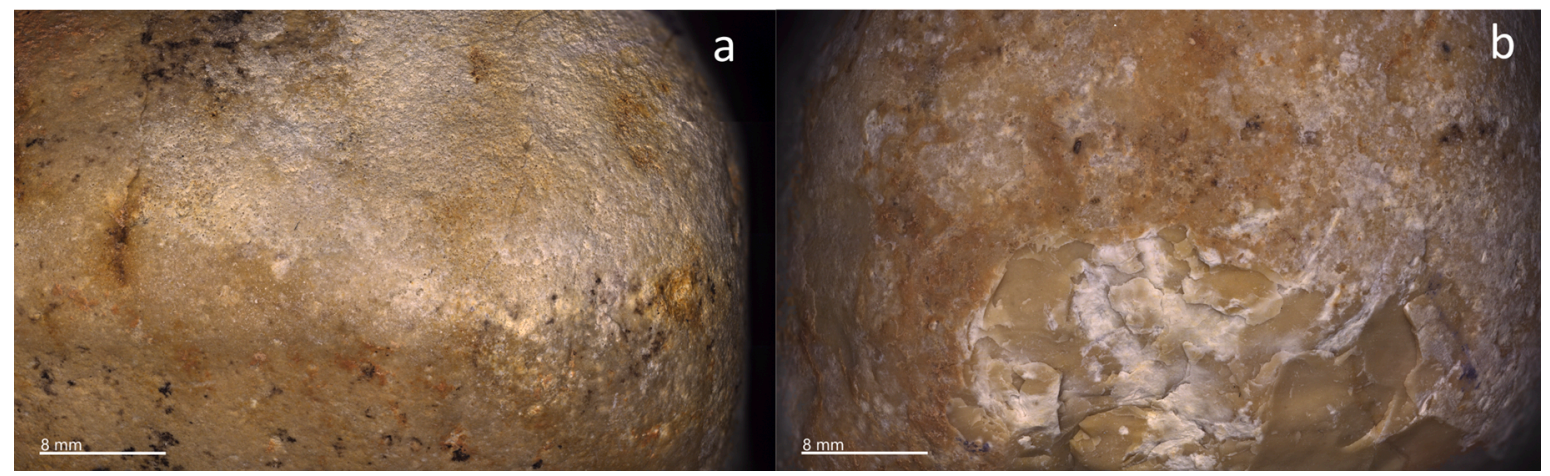

Fig. 4. Samples used for percussive experiments: a) Sample 3-6 (used for 500 impacts on bone); b) Sample 3-12 (used for 50 impacts on flint).
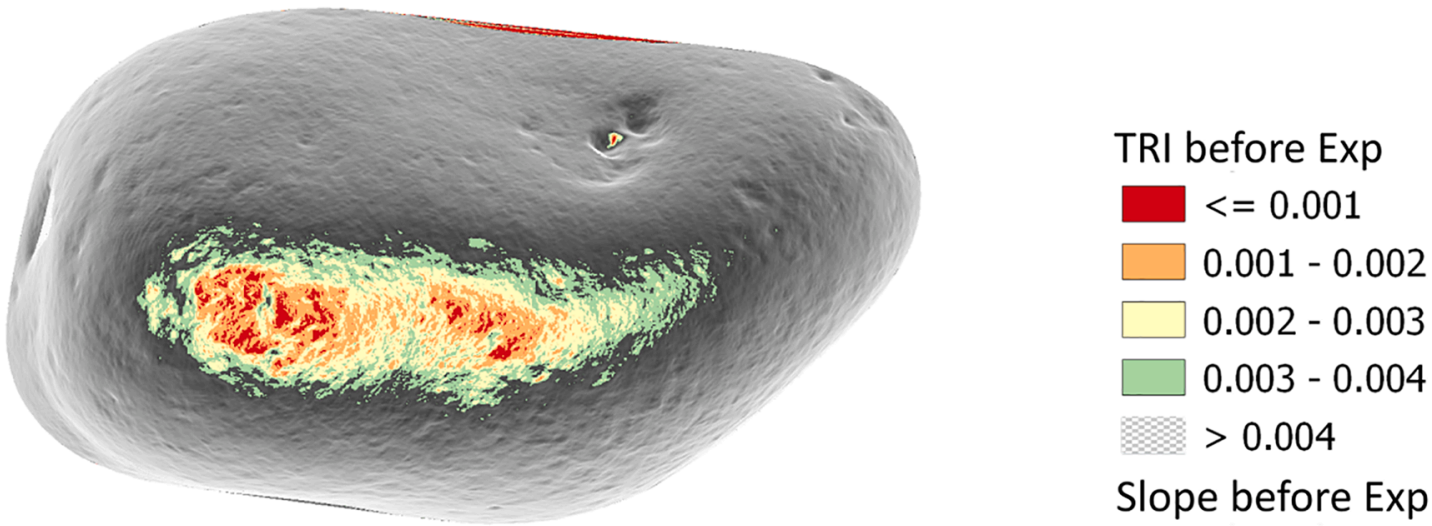

\section{Slope before Exp \\ 0.0412132 \\ 89.8448}

TRI after Exp

$<=0.001$

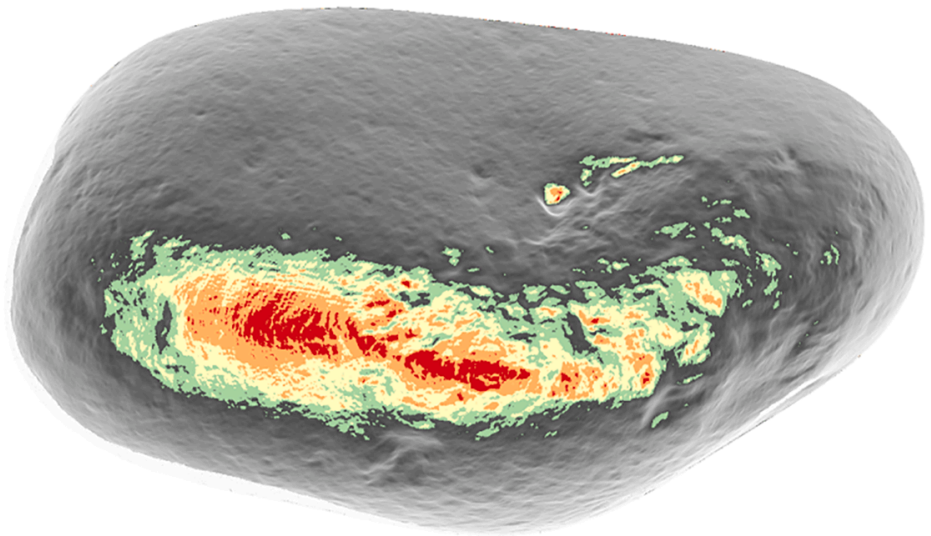

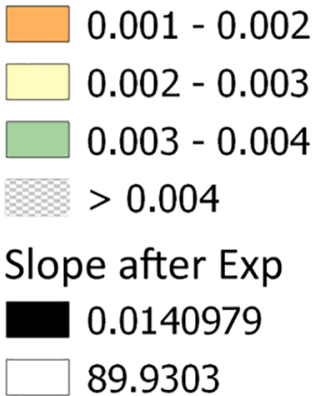

Fig. 5. Example of visualization of the TRI and Slope computation before and after experiments.

\subsection{Documentation and analytical procedure}

The use-wear developed on the experimental tools was analysed by adopting a multi-scale approach that combines analysis of 3D data from the scans and the images acquired with both low and high-power microscopy. Within this multi-scale approach, both qualitative and quantitative data were combined.
Following the well-established framework for GST use-wear analysis, our observations were organized in two main scales: macro and microwear traces. Wear traces were characterized and documented using the terminology used in previous publications (Adams, 2002, 2014; J. Adams et al., 2009; J. L. Adams, 2002; Dubreuil et al., 2015; Dubreuil \& Savage, 2014). Use-wear traces were systematized in three main categories: abrasive (e.g., striations, surface levelling), impact (surface 


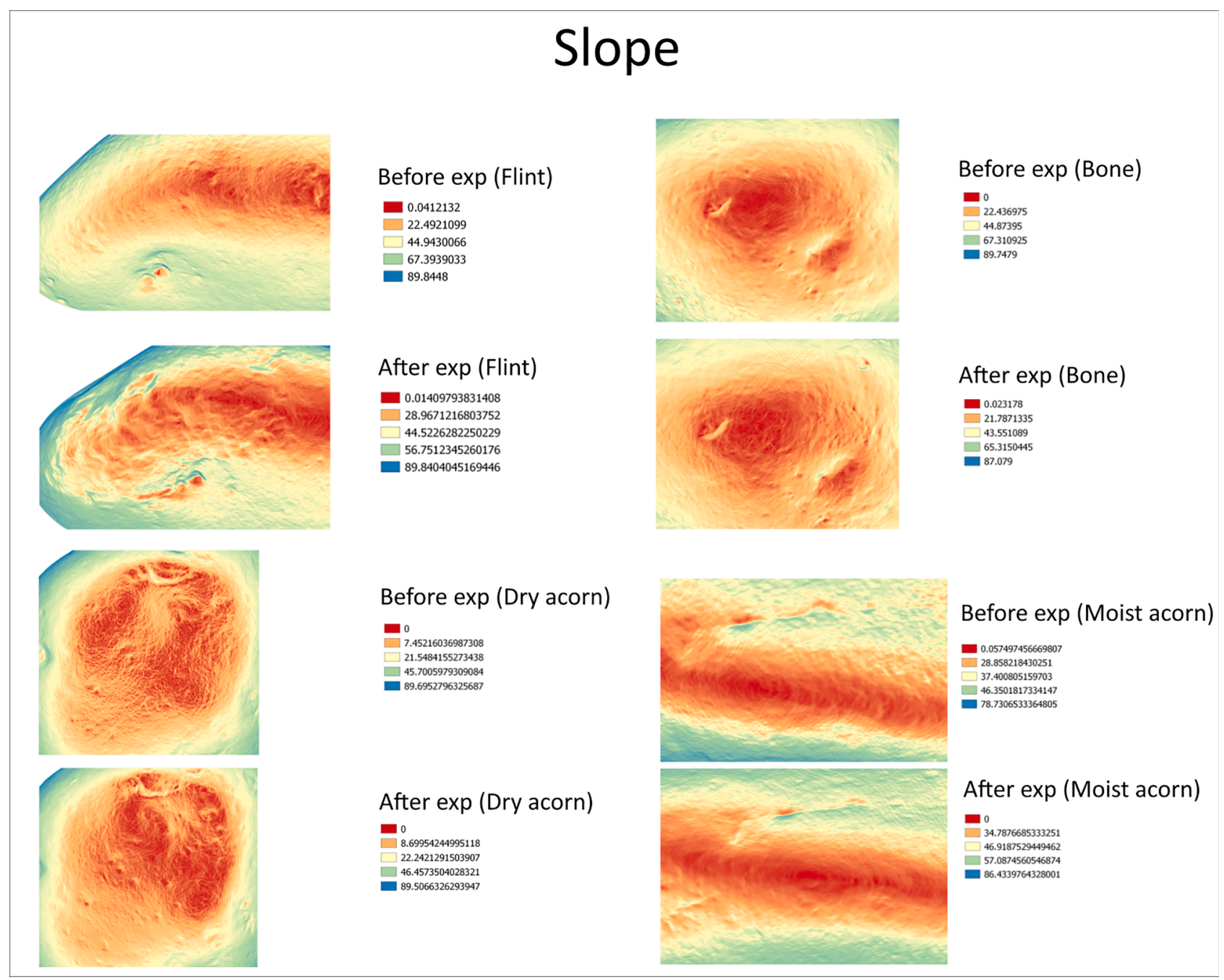

Fig. 6. Slope computation, showing examples from before and after the experiments for each activity before and after experiments.

macro fractures) and micro-polish (c.f. sheen).

\subsection{Macro-analyses (quantitative approach)}

In this work, all the samples were scanned with the HP 3D Structured Light Scanner Pro S3 (DAVID SLS-3), before and after the experimental cycles (acquisition settings in SOM 1).

The 3D point cloud of the 3D models was then exported as .csv file, which includes the $\mathrm{x}, \mathrm{y}$ and $\mathrm{z}$ coordinates for all measured points. The active surface was oriented and cut from the model using GOM Inspect (v2.0.1) and again exported as a .csv file. The 3D points cloud was used to generate raster files to be processed in GIS analyses using QGIS (v3.14.16-pi), creating DEMs, and to compute two terrain analyses for macro surface analysis and quantification: Slope, for measuring macro fatigue features, and Terrain Ruggedness Index (Riley et al., 1999) for measuring macro surface roughness.

The Slope algorithm measures the inclination and steepness of a surface plane defined by the cell and its eight surrounding neighbours. In our analysis, Slope was measured in degrees, ranging from 0 to 90 (Burrough and McDonell, 1998). The Terrain Ruggedness Index (TRI) can be described as the mean difference between a central pixel and its surrounding cells. Using this tool, terrain heterogeneity can be calculated by computing the sum change in elevation between a grid cell and its neighbourhood. This provides a relative measure of elevational changes between a specified grid cell and neighbours. In the resulting
DSM, a TRI value of 0 represents the baseline and the minimum degree of roughness (i.e., homogeneous surface; Riley et al., 1999).

We used a Python script to automate the computation of the Slope and TRI for the total surface area of all the experimental samples. From the total surface, a sampled area (representing the active area during the experiments) was extracted, and then converted to polygons to extract the table of properties containing the quantitative values for the Slope and TRI computation, including contour intervals, number of parts, number of points, and absolute perimeter and area for each part (see SOM 2 for the QGIS analysis protocol).

\subsection{Micro-analyses}

In order to get high quality images of the active surfaces at a macro scale, a digital microscope (ZEISS Smartzoom $51.6 x$ objective) was used to document the tools, before and after the experiments. The micropolished areas that formed during the experiments were analysed using a reflected light microscope (ZEISS Axio Scope.A1 MAT, objective EC Epiplan 10x/0.25 M27 FWD $=11.0 \mathrm{~mm}$ and Objective EC Epiplan 20x/0.4 M27 FWD $=3.2 \mathrm{~mm}$ ). During the analysis, all pictures were acquired with the dedicated software ZEISS Zen Core, using the image Extended Depth of Focus (EDF) stacking module to generate in-focus images. Polished surfaces were qualitatively categorized and described following such well-established terms as texture, contours, distribution and cross section morphology (Dubreuil et al., 2015; Dubreuil \& Savage, 


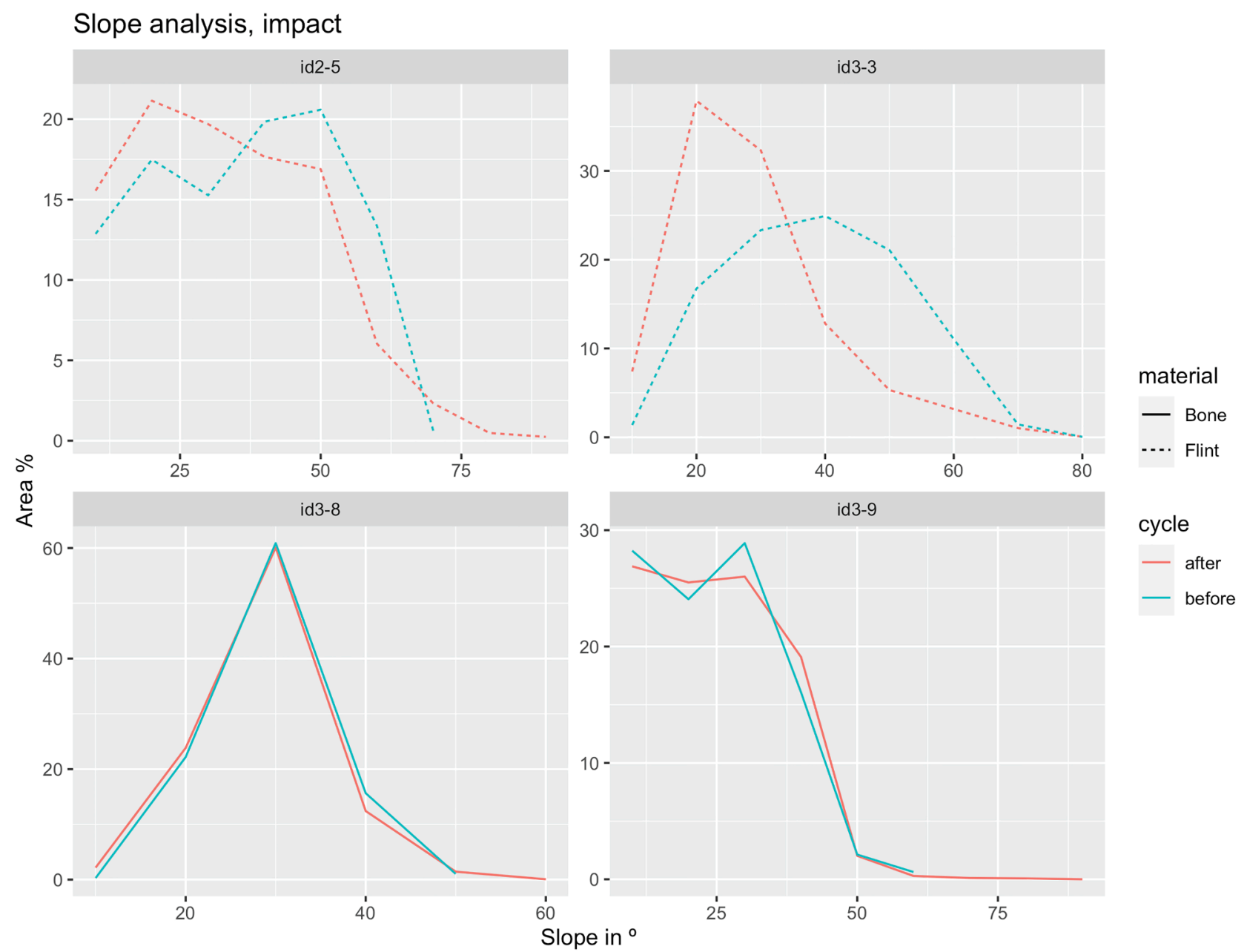

Fig. 7. Slope analyses, percentage of area plotted against slope degrees.

2014).

\subsection{Confocal microscopy}

Our qualitative characterization of the micro-polish was complemented by a preliminary attempt at micro surface quantification on these types of tools. In this study, two samples for each polished zone were measured with a 3D laser confocal microscope. For each sample, three different polished areas were scanned and processed. All microsurface texture acquisitions were done using a 3D Laser Confocal microscope (LSM 800 MAT mounted onto an Axio Imager.Z2 Vario light microscope, Carl Zeiss Microscopy GmbH). The C Epiplan-Apochromat $50 \times / 0.75$ objective was used for all data acquisitions. The field of view (FOV) was 255.6x255.6 $\mu \mathrm{m}$ and the pixel size (spacing) was $0.0852 \mu \mathrm{m}$ (see additional acquisition settings in SOM2).

The resulting 3D surface data were processed in batch in ConfoMap v8.1.9286 (a derivative of MountainsMap Imaging Topography developed by Digital Surf, Besançon, France). All surface processing and analysis was done using templates adapted from Calandra et al. (2020) for the surface roughness standard following ISO 25178-2 (ISO, 2005, 2012), furrow parameters, texture direction parameters, and texture isotropy parameters. The analysis workflow is detailed in SOM3 (the output files can be found here https://zenodo.org/record/4585357). When possible, three areas representative of the micro polish were measured in each sample; this was not possible for some samples due to the low degree of polish formation and non-diagnostic characteristics of the polished area.

All data analysis and plotting was processed in the open-source software $R$ (see SOM4 and https://github.com/jmmarreiros/Mech ExpGST). In this study, surface texture quantification was first explored using a small sample size for different actions and worked material. This initial test was mainly directed at evaluating the qualitative classification of the micro-wear traces identified and classified on experimental samples.

\subsection{Residue analyses}

Residues were also documented on the experimental tools after each activity, both in situ and using water extractions sampled from the tool surface, in order to document their visual appearance after the conclusion of the experiments. Only anvils were microscopically inspected, as they were the implements that were in contact with the worked material for the longest time ( 970 impacts and 3000 rotations).

In situ observation was performed using low-power equipment (ZEISS SteREO Discovery V8, $1 \mathrm{x}$ to $5 \mathrm{x}$ optical zoom). Samples of bone and acorns were collected from the limestone anvils for further analysis using a pipette (G P100G - GILSON $®$ ) and distilled water as a solvent (Cnuts \& Rots, 2017; Torrence \& Barton, 2016). The extracted residues were analysed under a transmitted light microscope (Zeiss Axio Lab.A1, $50 x / 0.8)$. Additionally, fragments of bone and acorns were manually extracted with metal tweezers from the two used anvils and ground using an agate mortar and pestle. Extracted residues were prepared by placing some drops of residue solution onto a clean microscope slide. The mounting media used was a $50 \%(\mathrm{v} / \mathrm{v})$ aqueous solution of glycerol. A slide cover was placed on each sample. This processing method is 
TRI analysis, impact
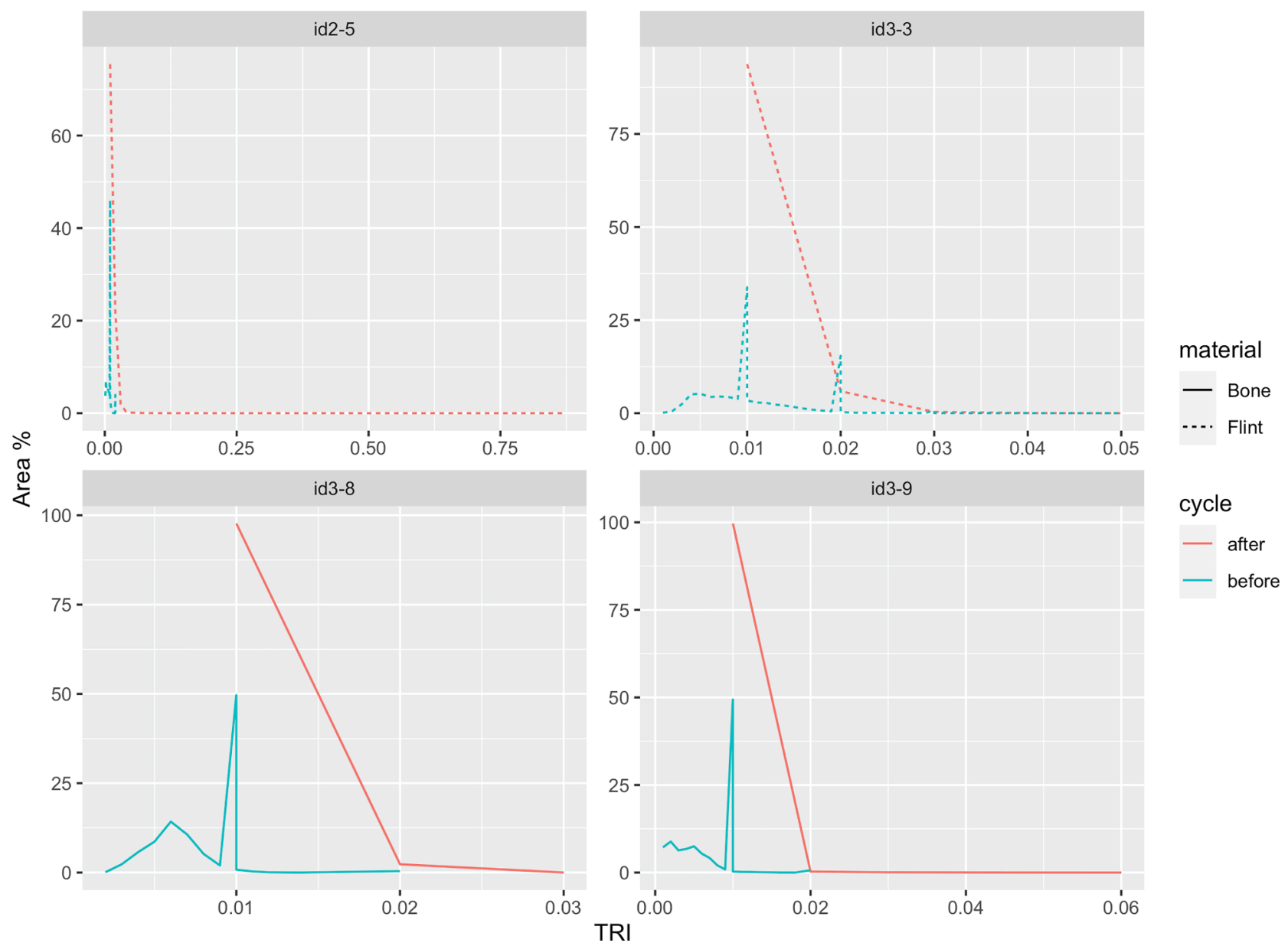

Fig. 8. TRI analyses, percentage of area plotted against TRI values.

adapted from Torrence and Barton (2016).

Slides were observed under both plane- and cross-polarized light. Residues were identified following visual comparisons with microscopic images presented in other publications (Gismondi et al., 2019; Li et al., 2020; Lippi, 2018). The documentation of bone and acorn residues both in situ and after extraction adds to other published reference collections for GST (e.g., Fullagar, 2014; Hayes, 2015).

\section{Results}

\subsection{Macro analysis}

\subsubsection{Naked-eye observation}

Impact experiments (bone and flint) produced clear differences in terms of impact marks and abrasive use-wear traces, recognizable even to the naked-eye. Under the same experimental design and controlled conditions (e.g., force, number of impacts, position) it is possible to verify that flint knapping produces more pronounced alterations of the surface topography, including deeper impact marks. Some experimental tools even flaked or broke after a few impacts (e.g. samples $2-10$ and 4-1) (Fig. 3).

Unlike flint knapping, the use-wear formed by bone breaking was difficult to identify with the naked eye. When 50 impacts were reached, these differences in macroscopic wear formation between bone breaking and flint knapping became obvious. We therefore decided to test if increasing tool use intensity (i.e., the number of impacts) in the bone breaking experiment would produce surface alterations (both fatigue and abrasive wear) in the range of what was observed in the flint experiment after a shorter period of use. To explore this question, the number of impacts was increased for several experimental tools, reaching up to 500 impacts for one of them.

Our results indicate that even after 500 impacts on bone (Fig. 4), the alterations on the surface can still be described as minimal, especially when compared to those displayed on the flint knapping tool used for a considerably smaller number of impacts (50).

On the other hand, unlike impact motions, grinding experiments of dry and moist acorns did not produce any visible surface alterations (e.g. fatigue or either smooth or rough surfaces) identifiable by the naked eye.

\subsubsection{Digital elevation models (DEM) and terrain surface analysis}

We used different types of computation and band colour classification to characterize and compare the topography of the surfaces, between and within experimental samples. Slope analyses clearly highlighted significant surface alterations resulting from the development of flattened spots on the active area after the experiments.

Fig. 5 shows how the different experiments modify the surface in terms of slope. Samples 3-3 and 2-5 (used for flint knapping) show an intense alteration when compared with the samples 3-8 and 3-9 (used for bone breaking). Alterations related to grinding appear poorly detectable at this scale of analysis.

Flint experiments produced surface alterations that are clearly detected and measured by slope quantification. These are marked by a clear increase in the percentage of areas with lower inclination angles. This means that the normal curvature of the stone was reduced by the 


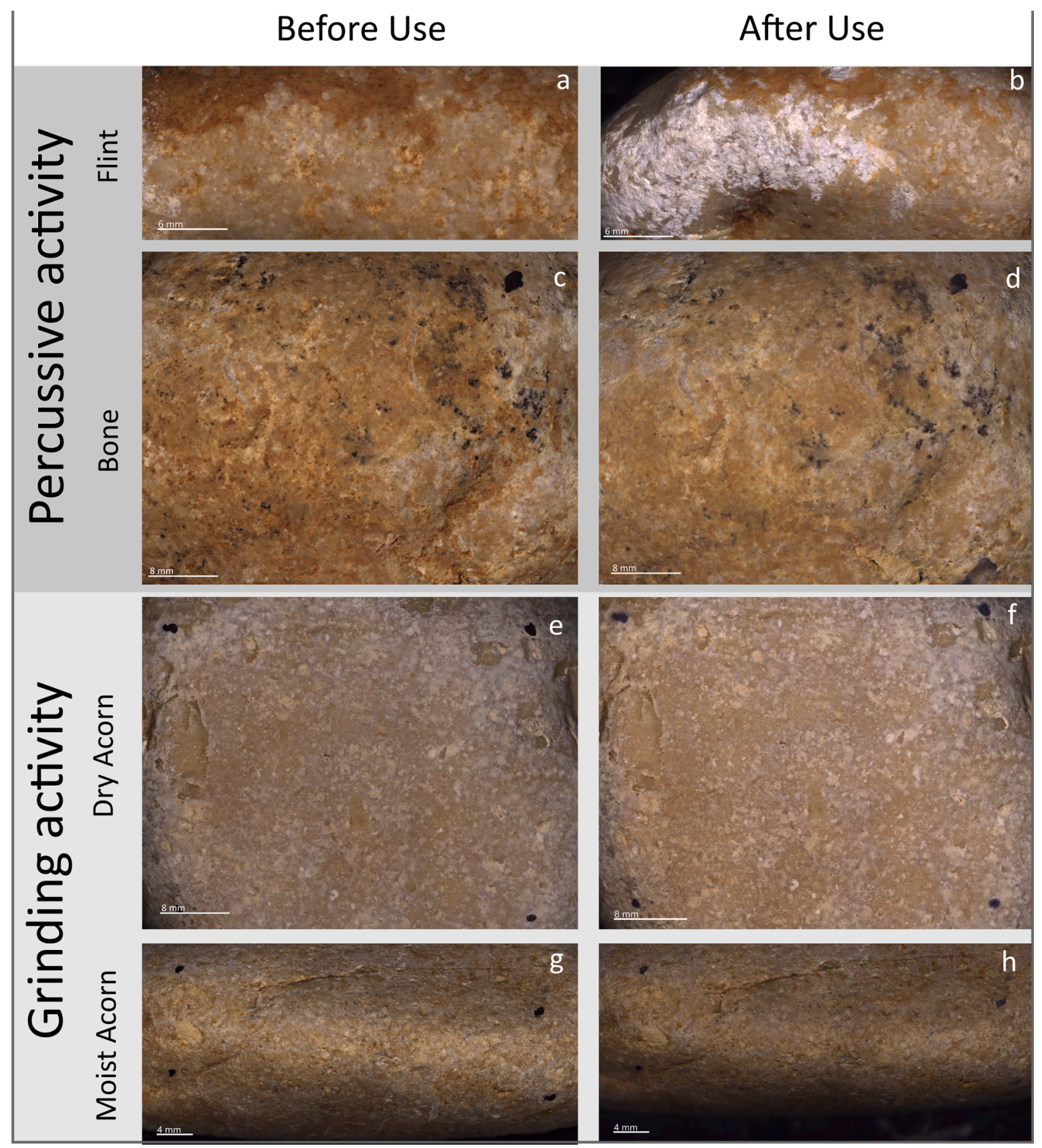

Fig. 9. Macro imaging of active surface: a) sample 3-3 before activity; b) sample 3-3 after 50 impacts on flint; c) sample 3-8 before activity; d) sample 3-8 after 50 impacts on bone; e) sample 6-1 before activity; f) sample 6-1 after 1000 rotations grinding dry acorn; g) sample 6-7 before activity; h) sample 6-7 after 1000 rotations grinding moist acorn. Details on all acquisition settings in SOM 1.

impacts, generating an increase of flattened areas. In sum, it is possible to conclude that these impact activities leave marks on the surface that are detectable and possible to measure by calculating the slope. However, the same computation did not detect significant alteration when applied to the sample used in grinding experiments. As is shown in Fig. 6, in this case, the distribution of the slope values did not change significantly after the experiments (Fig. 7).

The TRI model allows the alterations to be identified and quantified in terms of surface roughness (Fig. 5). When comparing before and after experimental cycles, the experiment with flint is again the one showing the most significant changes in both slope and roughness. Here, slope data shows a clear tendency for surface areas with lower slope values to increase after the experiments. TRI values including absolute values, area and perimeter measurements tend to increase after the experiments, which illustrates an increase in macro surface roughness. With the TRI it was possible to identify changes in the surfaces of the tools used for grinding experiments. TRI values after grinding show a tendency for a reduction in surface complexity, where the values tend to converge(Fig. 6,7,8).

\subsection{Low magnification microscopy}

Both sets of experiments (percussive and grinding) resulted in use-wear traces identifiable at low magnifications. As previously described, much deeper impact marks were observed on the stones used for flint knapping compared with those used for bone breaking. 
$100 x$
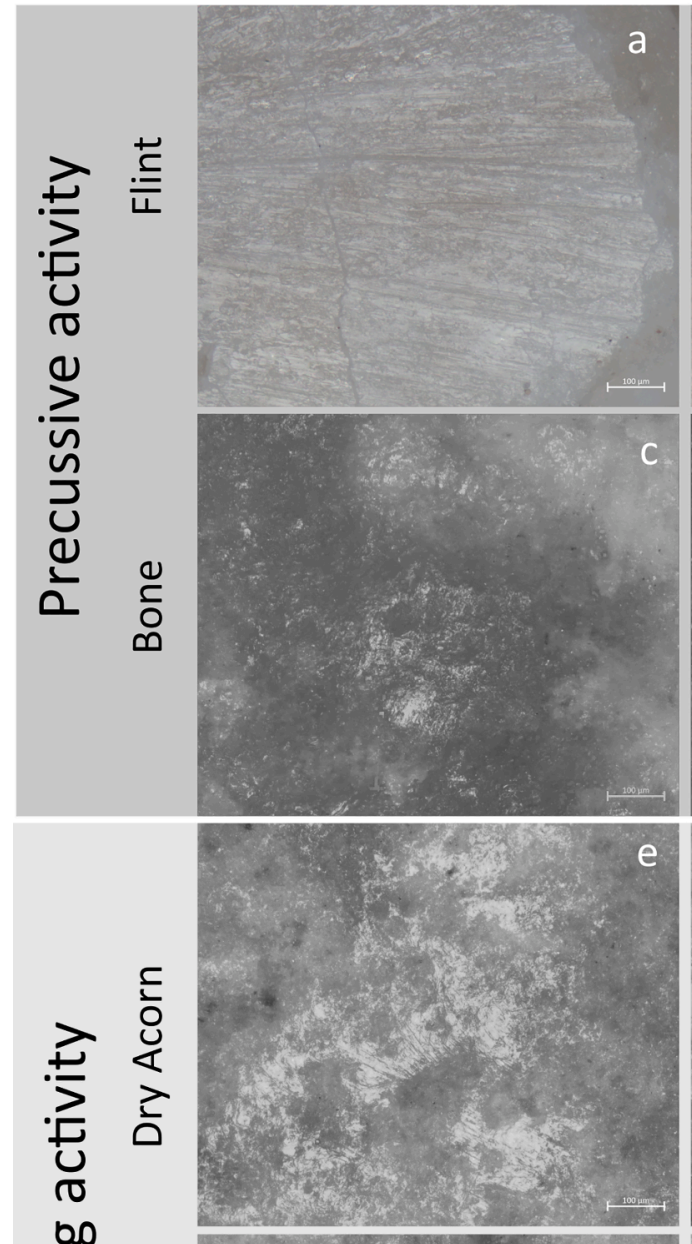

e
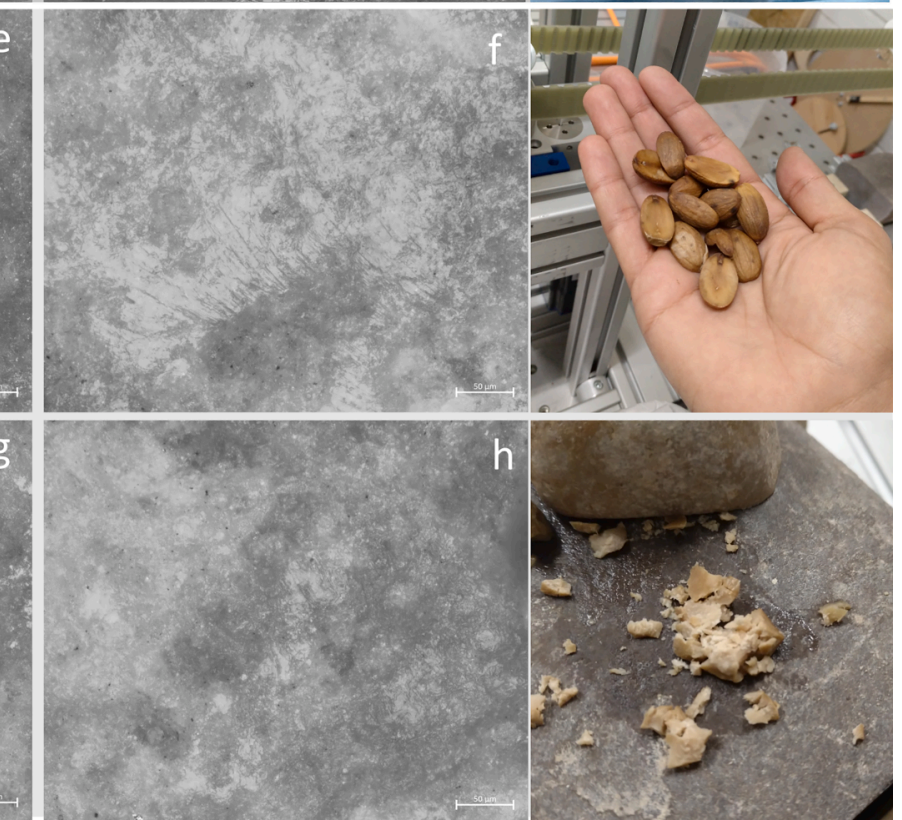

$200 x$
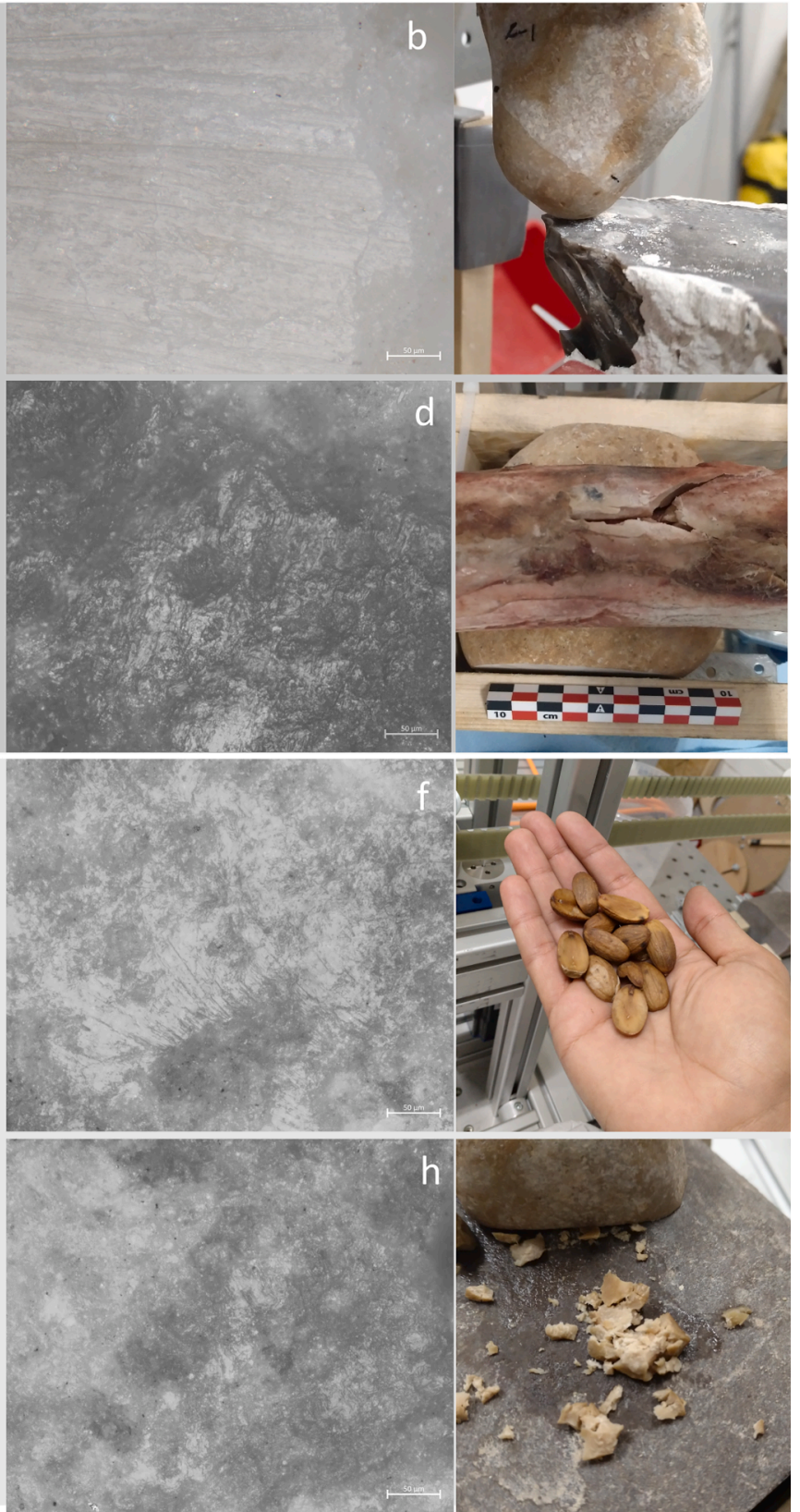

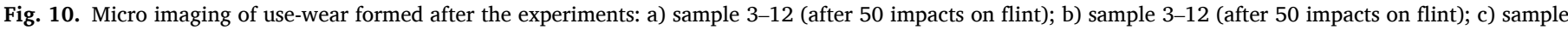

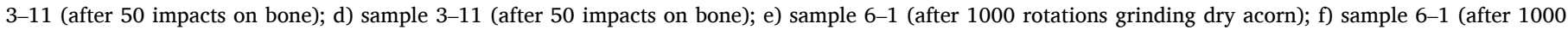

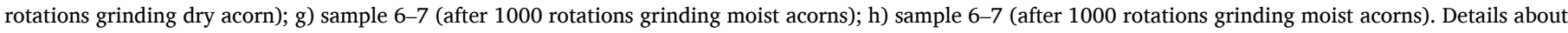
acquisition setting in SOM 1.

Flint knapping produced a great number of surface alterations, including abrasive traces characterized by a high frequency of macro striations, as well as fatigue wear dominated by grain crushing (Adams, 2014). Topographic deep depressions and occasional chipping or flaking was also observed on the flint knapping tools. At this scale, it is also possible to identify chromatic alterations, characterized by the development of white areas as the result of the crushed minerals (Fig. 8).

At low magnifications it is now possible to identify topographic alterations on the samples used for breaking bones. These are characterized by a low level of chromatic alterations and - unlike flint knapping - by smoothed surface areas. Here, macro striations are very rare, and the degree of mineral crushing is also very low.

With regards to acorn grinding: both activities on dry and moist acorn show significant differences compared to impact motions. All samples are void of clear macro traces identifiable under low magnification optical microscopes (Fig. 9).

\subsection{Micro analysis}

\subsubsection{High magnification microscopy}

At a micro scale, all experimental activities produced polished areas, which - based on our descriptive framework - are found to differ depending on the worked materials and activities (Fig. 9). Bone 
Table 2

Qualitative analytical description.

\begin{tabular}{ll}
\hline Qualitative description & Contact Material \\
Main features & Flint \\
\hline $\begin{array}{l}\text { Micro polish (i.e. sheen) } \\
\text { Generally only on high microtopography } \\
\text { Flat cross section } \\
\text { Rough texture }\end{array}$ \\
$\begin{array}{l}\text { Sharp contours } \\
\text { Frequent presence of abrasive tracks }\end{array}$ \\
$\begin{array}{l}\text { Domed cross section } \\
\text { Fluid texture }\end{array}$ \\
$\begin{array}{l}\text { Diffuse contours } \\
\text { Sparse distribution }\end{array}$ \\
$\begin{array}{l}\text { Penetrating on low } \\
\text { Domed cross section } \\
\text { No striations }\end{array}$ \\
\\
$\begin{array}{l}\text { Generally, only on high microtopography } \\
\text { Flat cross section }\end{array}$ \\
$\begin{array}{l}\text { Rough texture } \\
\text { Frequent presence of linear striations }\end{array}$ \\
\hline
\end{tabular}

breakage produced polished areas characterized by a fluid texture, domed cross section and diffuse contours. Moreover, such polishes were found on both peaks and interstices of the surface microtopography. The polish resulting from flint knapping was generally observed only on the highest topographical parts, and presented flat cross sections, rough texture, and sharp contours. This type of polish also appears frequently in association with deep striations and abrasive tracks.

The micro-polish developed on the samples used for grinding both dry and moist acorns shows different characteristics, which is most likely dependent on the moisture level of the acorn. The processing of dry acorns produced a well-developed polish that is more extensive compared to the polish produced from processing moist acorns. Other aspects such as rough texture and sharp contours with frequent development of striations have been identified. On the other hand, the polish formed after contact with moist acorns is less developed, showing a more fluid texture, and the contours are very diffuse (Fig. 10 and Table 2).

\subsubsection{Laser scanning microscopy}

Through laser scanning microscopy it was possible to acquire quantitative data based on the analyses of area-scale parameters ISO 25178, including height and volume, allowing comparison between the polishes developed by different activities and contact materials.

Although there are some features that overlap between the polishes formed by different activities, the analysis shows that the polishes associated with percussive activities tend to present higher values in most of the parameters (Fig. 11). This aspect is even more clear on the mean density of furrows as shown on Fig. 13. While there is no overlap between bone and dry acorn polishes (except for one single parameter: $\mathrm{Sku}$ ), it is interesting to note that both tend to form a more consistent range of values between measurements from each group. The opposite scenario occurs with moist acorns, where the variation in values tends to be higher for most of the parameters (Fig. 12). In the case of the moist acorns, values seem less diagnostic since for most of the parameters these tend to present a considerable overlap with those of other polishes formed by other contact materials. However, all other materials (bone, flint and dry acorn) tend to form a distinctive signal that is easily illustrated by the plot of both height and volume parameters. (Fig. 13

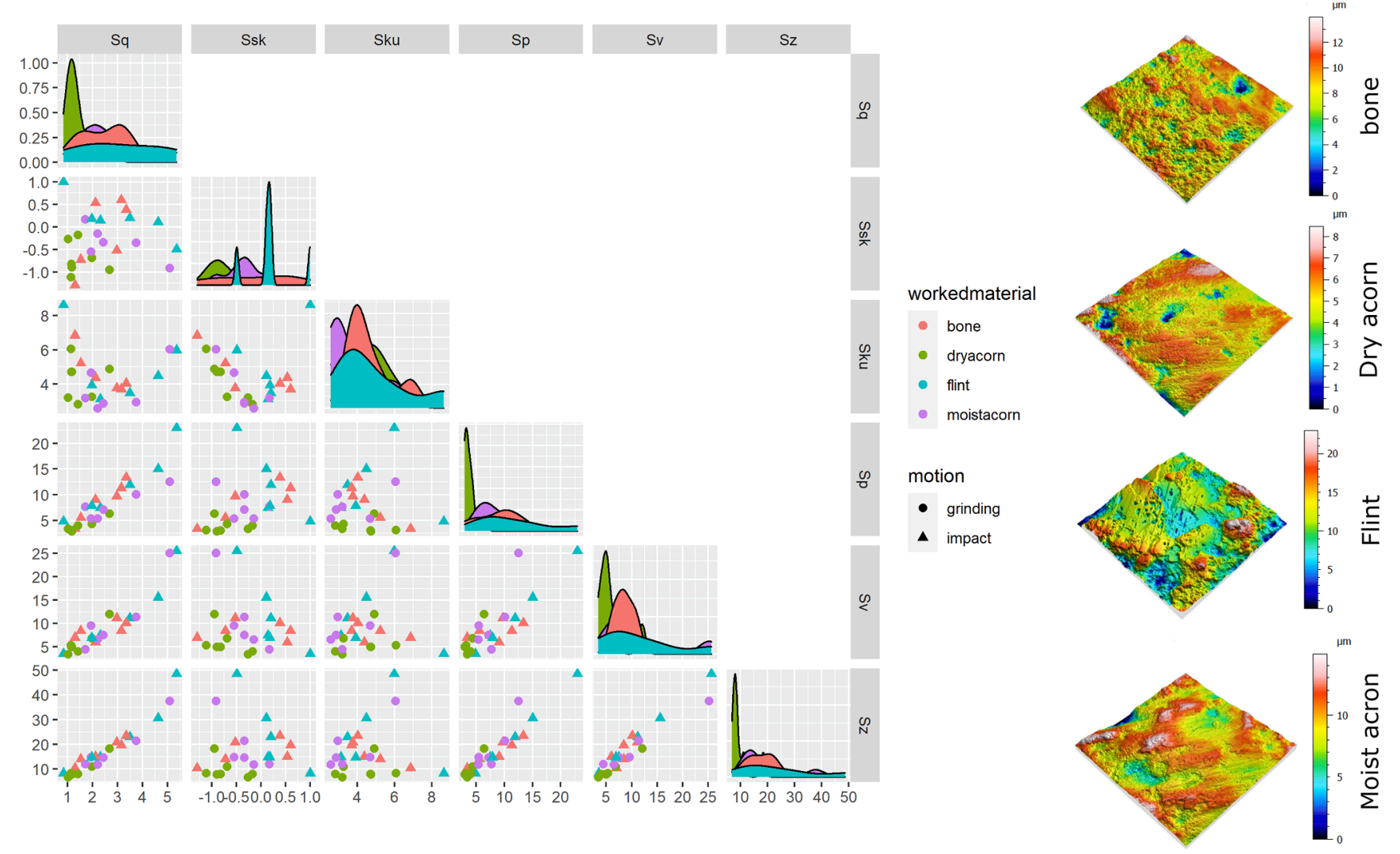

Fig. 11. Micro surface texture analysis (Height parameters) organized by the different types of polish. 

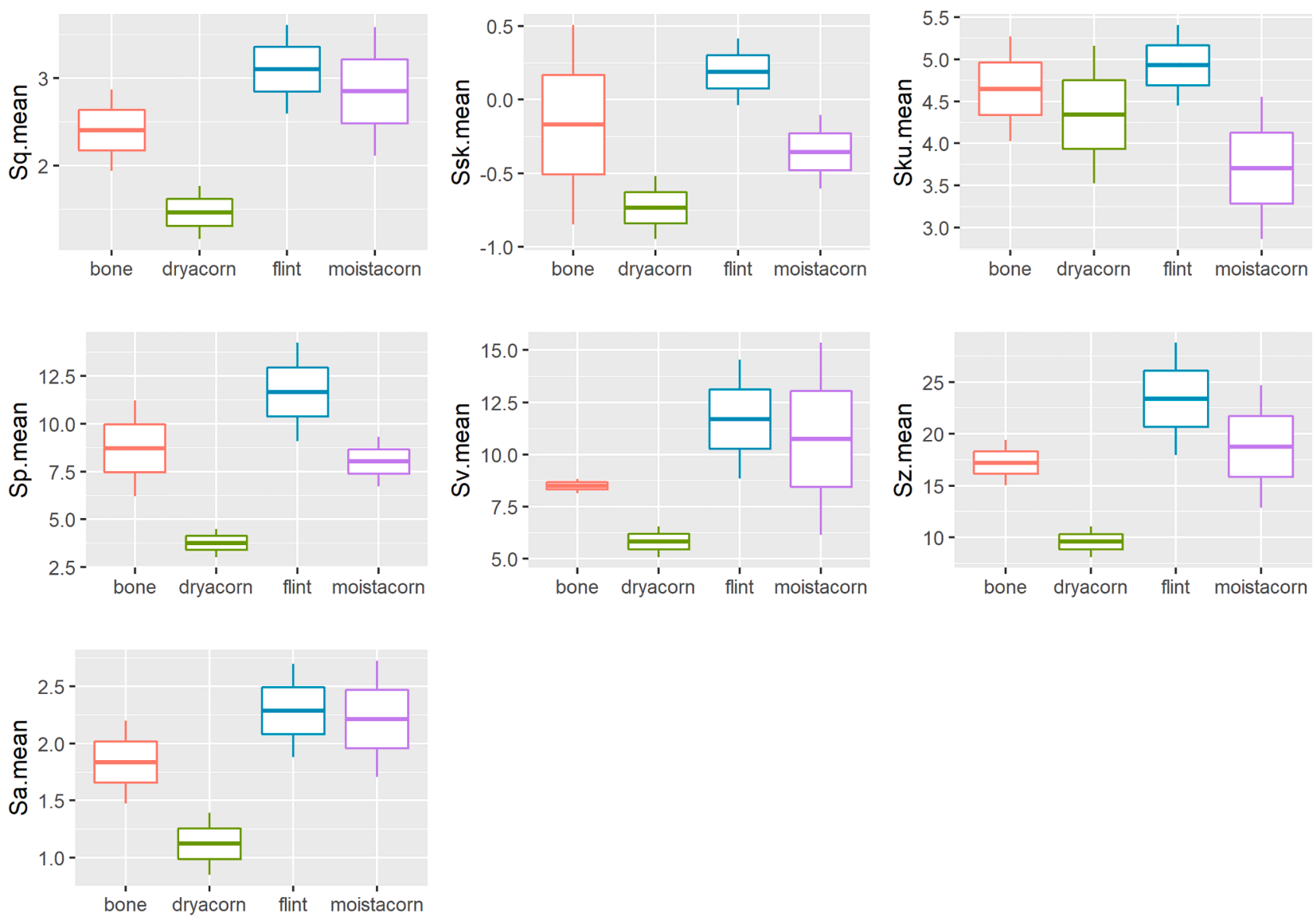

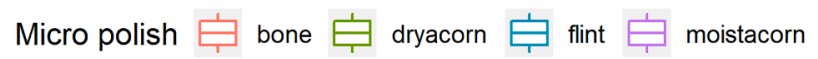

Fig. 12. Boxplots with the values of the micro surface texture analysis (height parameters) organized by the different types of polish.

and Table 3)

\subsubsection{Experimental residue remains}

The anvil used in the experiments with flint (anvil-flint) did not retain any flint micro-debris. This can be explained by considering the hardness of the flint nodules and the repetitive striking of the softer limestone surface. This sequence of movements quickly leads to a flattening of the anvil's contact area and a general "powder effect" (Fig. 8: b). No micro-debris were observed in situ on the surfaces of the flint knapping tools and therefore no residue extractions were taken from these specimens.

Bone residues on anvils were relatively abundant on the surfaces of anvil 2-2. Relatively large patches of smashed bone were visible on the active area (Fig. 14: a-c). Loose bone fragments and fibres were also present (Fig. 14: b-c). Pipette-extracted residues from bone were characterized by low degrees of birefringence (Fig. 14: d-f). Both inorganic and organic matters are visible, the latter being recognizable due to their brownish/reddish tones (Fig. 14: d-f). Mechanically extracted residues from the same area appeared as amorphous chips where the absence of organic material is evident (Fig. 14: g-i). The anisotropic orientation of the bone mineral crystallites typical of bone is only visible at higher magnifications (Fig. 14: f-i).

Several fragments of acorns were observed on the anvil used in the grinding experiments (sample 6-10). This anvil was particularly suitable for recovering residues, as it presented several holes on the surface which facilitated the entrapment of particles of the worked material
(Fig. 15: a-c). Smeared residues were also observed on microtopographical depressions of the active limestone area (Fig. 15 d-e), and powdered micro particles were documented on the lowest topographical parts (Fig. 15: f). (Fig. 14)

Observation on pipette-extracted samples showed a high abundance of starch grains and plant structures (Fig. 15: g-i). Starch grains were more abundant on the slides prepared after mechanical extraction of an acorn fragment (shown in Fig. 15: c) and laboratory grinding (Fig. 15: j1). On these specimens - in contrast to the pipette-extracted samples starches were organized into clusters (Fig. 15: j-k). Starch grains were consistent with the morphology and size descriptions of the English oak (Quercus robur) species (Gismondi et al., 2019; Lippi et al., 2015). The observed granules comprise round to oval shaped forms and range in size from 5 to $15 \mu \mathrm{m}$. Lamellae are indistinct and hila are invisible (Fig. 13: g-h, j-k), while birefringence is well defined (Fig. 13: i, l).

(Fig. 15)

\section{Discussion}

As for many other artifacts, one of the primary challenges when studying GSTs is to distinguish alterations caused by humans from those resulting from natural and post-depositional processes (Caruana et al., 2014). In this endeavour, archaeologists have often used qualitative criteria derived from singular experiments or empirical observations, an approach which has been criticised for being too subjective. 

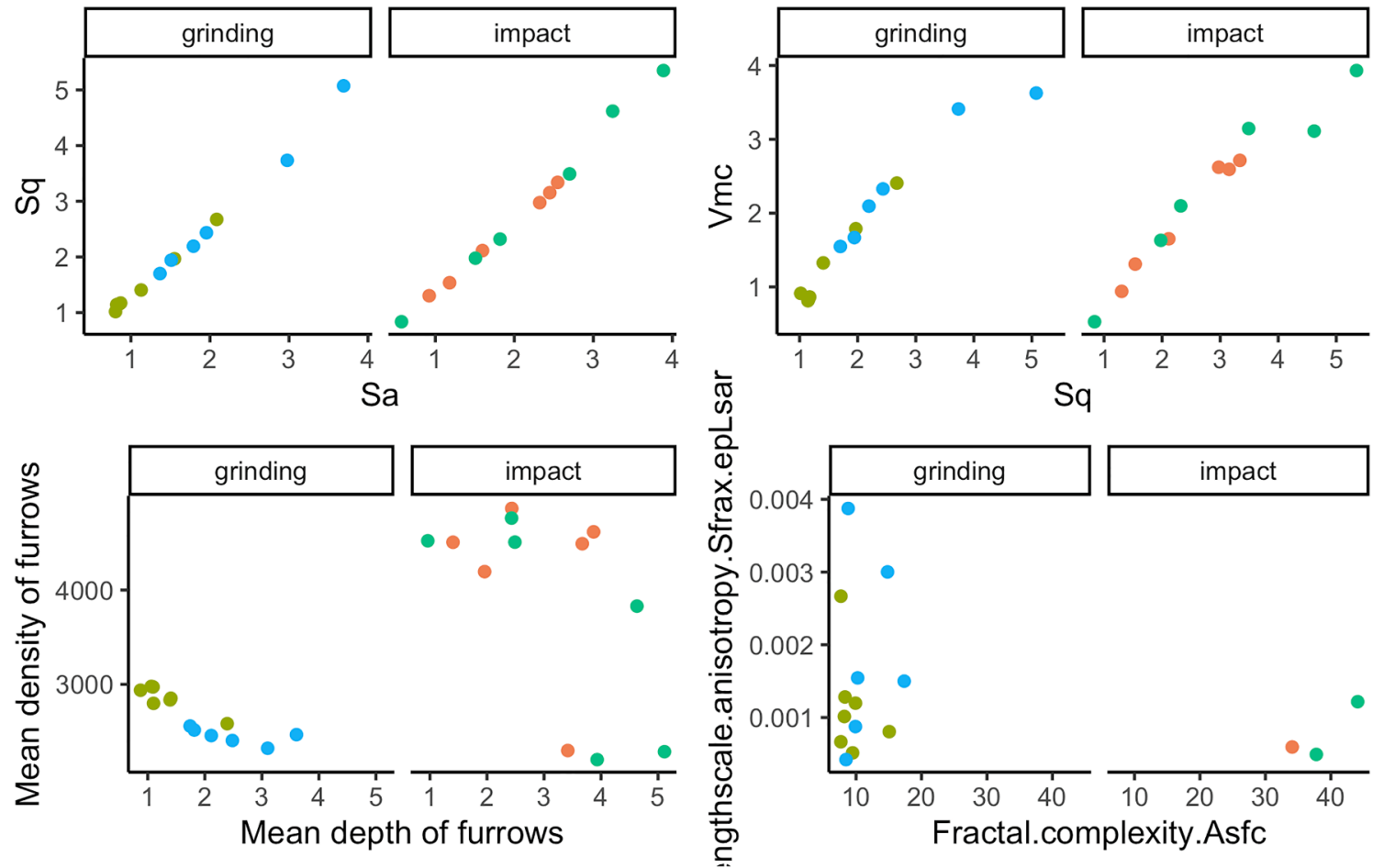

workedmaterial b bone dryacorn - flint $\bullet$ moistacorn

Fig. 13. Scatterplot combining the analysis of different parameters for micro surface texture quantitative analyses.

Use-wear analysts have been developing frameworks to help in this crucial task, and to further explore past tool function and ancient technology. Rather than being 'focused', the use-wear approach is holistic as it starts by assessing the shape of the tool and localizing the prehensive and active areas. The location of the use-wear on a tool's surfaces is very important, revealing patterns of wear trace concentration and distribution different from the natural or postdepositional alterations which may appear in more arbitrary locations. Beside location, it is also important to understand the combination of macro and micro diagnostic features of use-wear that can be related to contact with some type of material, and/or different types of actions.

With the goal of better understanding the GST technology discovered at the MP site of Nesher Ramla, we performed a series of experiments with limestone cobbles used to process flint and bone. These materials are commonly transformed through percussive activities and both broken bones and flaked flint materials appear in high frequencies at the site (Centi \& Zaidner, 2020; Crater Gershtein et al., 2020; Prévost \& Zaidner, 2020; Zaidner et al., 2014). Based on the diversity of micropolish types previously identified in the Nesher Ramla's GST assemblage, we also included other types of activities in our experimental program (Paixão et al., in press). Specifically, a set of experiments involving grinding motions on vegetal matter (i.e., dry and moist acorns) was performed, allowing the exploration of different contexts of wear development.

The experimental data and the multi-scale-based approach presented in this paper has allowed a detailed description of the use-wear patterns associated with each specific type of use. Considering our preliminary analysis of the archaeological materials and the variability observed, our experimental program followed a mechanical design aiming at achieving two major goals: 1) differentiating GSTs from unused items, and 2) understanding how the tools were used.

Our experimental program followed a mechanical design with standardized and reproducible settings (in terms of action/motion). This level of standardization cannot be achieved with manual experiments, and allows variables to be isolated during experiments, which is crucial for identifying causality in the formation of use-wear traces. However, we do not think that mechanized experiments can or should replace manual experiments. Mechanized systems can be used to explore specific questions which necessitate precise variable control, and simultaneously can offer higher levels of reproducibility. Nevertheless, the data derived from mechanized experiments should ultimately be seen as complementary to those derived from manual experiments.

Our use-wear results indicate that the cobbles used to strike flint are characterized by more pronounced alterations at a macro scale level, when compared with samples used in bone breaking experiments. In our experiments, these differences developed at an early stage and are not related to the intensity of tool use (in this study represented by a reduced number of impacts). Damages on the bone breaking tool surfaces remain less extensive even after a substantial number of strikes. This may seem to contradict previous studies pointing out an overlap in use-wear between flint and bone breaking tools. It should be noted, however, that the most obvious use-wear reported in manual experiments with bone fragmentation corresponds to fatigue wear which likely develops when a hammerstone accidentally strikes an anvil (Benito-Calvo et al., 2018; Pop et al., 2018). This may occur more frequently in manual experiments. Further in-depth comparison with manual experiments will be important here. Nevertheless, both manual experiments and the mechanical ones presented here suggest a low and slow development of macroscopic use-wear on bone breaking tools (Benito-Calvo et al., 2018a, 2018b; de la Torre et al., 2013).

The grinding experiments produced the less conspicuous macro-wear in our sample, showing no clear difference from the unused natural surface to the naked eye. Several hypotheses can be suggested to explain this phenomenon. This can be related to the low intensity of use, to some mechanical limitation in terms of the activity itself produced by the machine, or ultimately it also can be related to variability in the raw material. In general, it can be said that low/long development of use- 
Table 3

List and description of parameters for surface texture analysis (adapted from Schulz et al. 2013) .

\begin{tabular}{|c|c|c|c|c|c|c|}
\hline $\begin{array}{l}\text { Scale } \\
\text { type }\end{array}$ & Standard & Category & Sub-category & Parameter & Description (condition) & Unit \\
\hline \multirow[t]{47}{*}{$\begin{array}{l}\text { Area- } \\
\text { scale }\end{array}$} & $\begin{array}{l}\text { ISO } 25178- \\
2\end{array}$ & Field & Height & Sq & $\begin{array}{l}\text { standard deviation of the height distribution, or RMS surface } \\
\text { roughness }\end{array}$ & $\mu \mathrm{m}$ \\
\hline & & & & Ssk & skewness of the scale limited surface & no unit \\
\hline & & & & Sku & kurtosis of the scale limited surface & no unit \\
\hline & & & & $\mathrm{Sp}$ & maximum peak height & $\mu \mathrm{m}$ \\
\hline & & & & $\mathrm{Sv}$ & maximum pit height & $\mu \mathrm{m}$ \\
\hline & & & & $\mathrm{Sz}$ & maximum height of the scale limited surface & $\mu \mathrm{m}$ \\
\hline & & & & Sa & arithmetical mean height or mean surface roughness & $\mu \mathrm{m}$ \\
\hline & & & Spatial & Sal & auto-correlation length $(\mathrm{s}=0.2)$ & $\mu \mathrm{m}$ \\
\hline & & & & Str & aspect ratio $(\mathrm{s}=0.2)$ & no unit \\
\hline & & & & Std & direction & $\circ$ \\
\hline & & & Hybrid & Sdq & root mean square gradient of the scale limited surface & no unit \\
\hline & & & & Sdr & developed interfacial area ratio of the scale limited surface & $\%$ \\
\hline & & & & Smr & $\begin{array}{l}\text { areal material ratio function of the scale limited surface (c }=1 \mu \mathrm{m} \\
\text { under the highest peak) }\end{array}$ & $\mu \mathrm{m}$ \\
\hline & & & & Smc & areal material ratio function of the scale limited surface $(p=10 \%)$ & \\
\hline & & & $\begin{array}{l}\text { Function and related } \\
\text { parameters }\end{array}$ & Sdc & Surface Section Difference (extension of the Rdc) & \\
\hline & & & & Sxp & $\begin{array}{l}\text { peak extreme height difference in height between } \mathrm{p} \% \text { and } \mathrm{q} \%(\mathrm{p}= \\
50 \%, \mathrm{q}=97.5 \%)\end{array}$ & $\mu \mathrm{m}$ \\
\hline & & & & $\mathrm{Vm}$ & material volume at a given height $(\mathrm{p}=10 \%)$ & $\begin{array}{l}\mu \mathrm{m} 3 / \\
\mu \mathrm{m} 2\end{array}$ \\
\hline & & & & Vv & void volume at a given height $(\mathrm{p}=10 \%)$ & $\begin{array}{l}\mu \mathrm{m} 3 / \\
\mu \mathrm{m} 2\end{array}$ \\
\hline & & & & Vmp & material volume of peaks $(\mathrm{p}=10 \%)$ & $\begin{array}{l}\mu \mathrm{m} 3 / \\
\mu \mathrm{m} 2\end{array}$ \\
\hline & & & & Vmc & material volume of the core $(\mathrm{p}=10 \%, \mathrm{q}=80 \%)$ & $\begin{array}{l}\mu \mathrm{m} 3 / \\
\mu \mathrm{m} 2\end{array}$ \\
\hline & & & & Vvc & void volume of the core $(\mathrm{p}=10 \%, \mathrm{q}=80 \%)$ & $\begin{array}{l}\mu \mathrm{m} 3 / \\
\mu \mathrm{m} 2\end{array}$ \\
\hline & & & & Vvv & void volume of the valley $(\mathrm{p}=80 \%)$ & $\begin{array}{l}\mu \mathrm{m} 3 / \\
\mu \mathrm{m} 2\end{array}$ \\
\hline & & & Related to segmentation & Spd & density of peaks & $1 / \mu \mathrm{m} 2$ \\
\hline & & & & $\mathrm{Spc}$ & arithmetic mean peak curvature & $1 / \mu \mathrm{m}$ \\
\hline & & & & S10z & ten-point height of the surface & $\mu \mathrm{m}$ \\
\hline & & & & S5p & five-point peak height & $\mu \mathrm{m}$ \\
\hline & & & & S5v & five-point peak height & $\mu \mathrm{m}$ \\
\hline & & & & Sda & mean dale area & $\mu \mathrm{m}$ \\
\hline & & & & Sha & mean dale area & $\mu \mathrm{m}$ \\
\hline & & & & $\mathrm{Sdv}$ & closed dales volume & $\mu \mathrm{m} 3$ \\
\hline & & & & Shv & closed hills volume & $\mu \mathrm{m} 3$ \\
\hline & & Furrow analysis & & madf & $\begin{array}{l}\text { maximum depth of furrows according the }=\text { vectorisation of the } \\
\text { micro-valley network }\end{array}$ & $\mu \mathrm{m}$ \\
\hline & & & & metf & mean depth of furrows & $\mu \mathrm{m}$ \\
\hline & & & & medf & mean density of furrows & $\mathrm{cm} / \mathrm{cm} 2$ \\
\hline & & Texture direction & & $\operatorname{Tr}$ & direction isotropy & $\%$ \\
\hline & & & & $\operatorname{Tr} 1 \mathrm{R}$ & first Direction & $\circ$ \\
\hline & & & & $\operatorname{Tr} 2 \mathrm{R}$ & second Direction & $\circ$ \\
\hline & & & & $\operatorname{Tr} 3 \mathrm{R}$ & third Direction & $\circ$ \\
\hline & & & & IsT & isotropy & $\%$ \\
\hline & & Scale Sensitive Fractal & & & Smooth-rough crossover & \\
\hline & & Analysis & & & & \\
\hline & & & & & Maximum relative length/area (Sdr on a surface) & \\
\hline & & & & & Fractal dimension & \\
\hline & & & & & Complexity (Similar to Sdq) & \\
\hline & & & & & Scale of maximum complexity & \\
\hline & & & & & Regression coefficient $\mathrm{R}^{2}$ & \\
\hline & & & & & Heterogeneity of complexity & \\
\hline
\end{tabular}



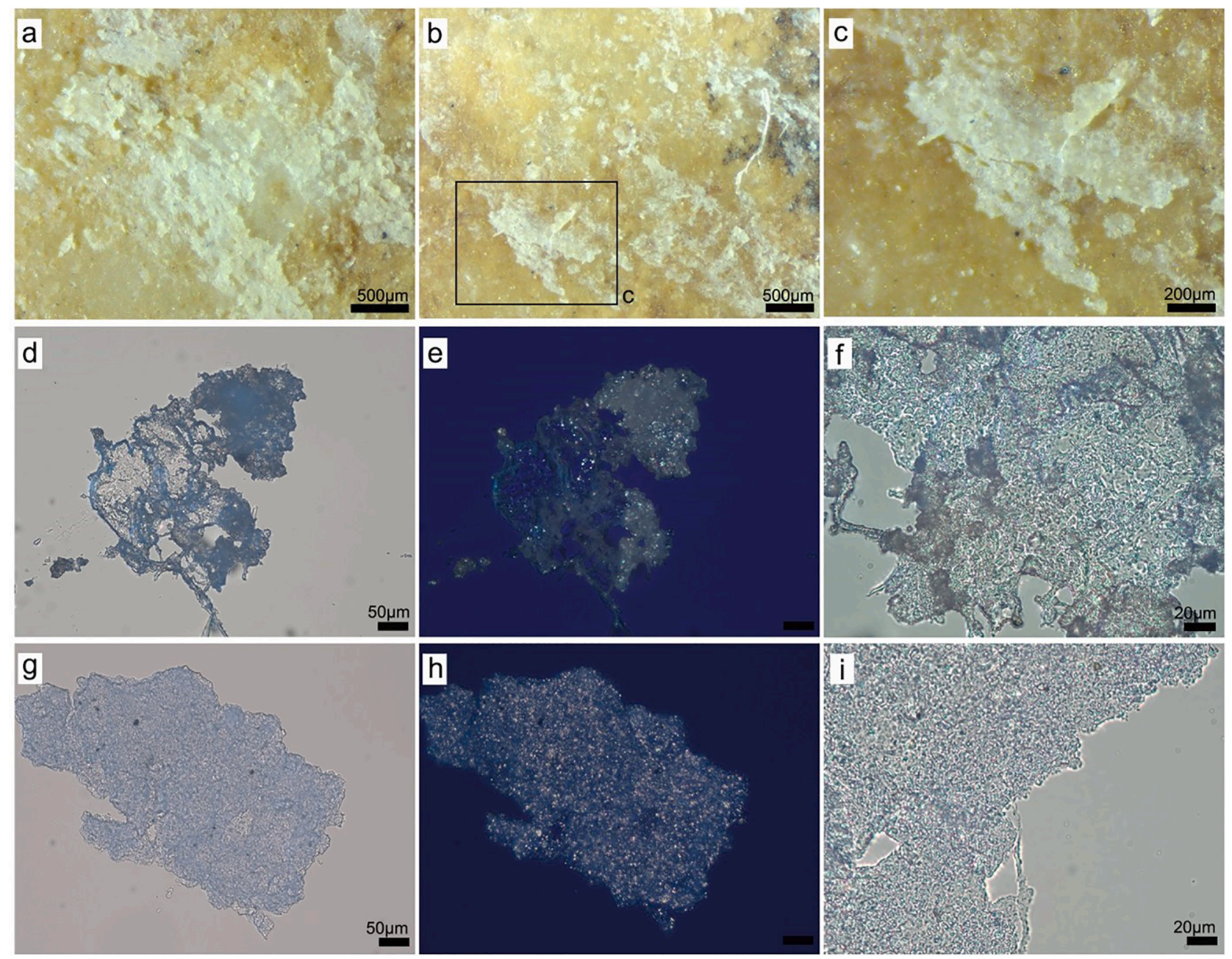

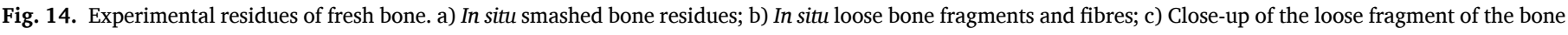

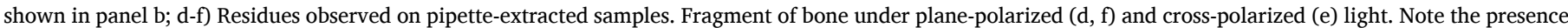

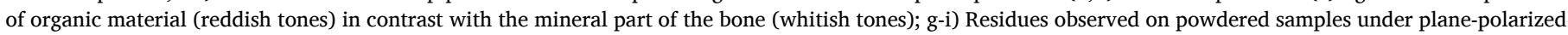
$(\mathrm{g}, \mathrm{i})$ and cross-polarized (h) light.

wear patterns is frequently observed in experiments with GSTs (Dubreuil et al., 2015). All these questions highlight the importance of continuing the experimental program, by increasing the intensity of use. Comparison with manual experiments would also prove to be important.

At a micro level, all the processed materials produced polished areas, and the characteristics of the different micro-polish appear significantly different. The bone experiments developed polished areas that are more penetrating in the lower micro topography, with domed cross section, fluid texture and more diffuse contours, while the flint contact tends to produce polished areas more restricted to the high micro topography, with flat cross sections, rough texture, and sharp contours. The formation of deep abrasive tracks is also very frequent. These observations show that use-wear studies should combine different scales of analysis as well as sampling strategies that are not biased by tool forms or clear absence/presence of damage traces identified based on preliminary evaluations (see Marreiros et al., 2020 for more on this discussion).

During the qualitative analysis at the micro scale, we identify overlap in some of the features of the polish formed by flint and dry acorn, namely (in terms of the cross sections): polish contours and patterns of striations. However, when combining and comparing macro and micro traces, it was possible to clearly distinguish the usewear formed by those two activities since the flint contact produces a high level of macro surface alteration (e.g. fatigue, mineral crushing, and some level of shipping, flaking), while the acorn produces almost no clear macro surface changes. The application of confocal analysis to the micro polish also supports this distinction between those two types of polish, where it was possible to verify the absence of overlaps for most of the parameters used in micro surface analysis. This example highlights the importance of combining different scales of analysis, and of integrating quantitative approaches to complement the qualitative analyses.

Nevertheless, it is also important to bear in mind that a quantitative approach on use-wear, based on surface texture analysis parameters, still lacks comprehensive reference collections to which the archaeological artifacts can be compared. On the same level - and beyond the scope of this study - much needs to be done in terms of understanding which parameters report better changes on tools surface caused by different actions and worked material. Our study represents a first attempt, and additional work still needs to be done.

The overlap of values from significant motions (such as pounding and grinding) and contact materials raises questions of which mechanical properties and other variables could affect changes on tools surface texture analysis. Our experiments demonstrate that the contact material can be differentiated in terms of use-wear, even when performing the same type of motion. Being aware of the limited range of activities tested here, we suggest that our results should be used as a baseline for helping use-wear analysts identify general 

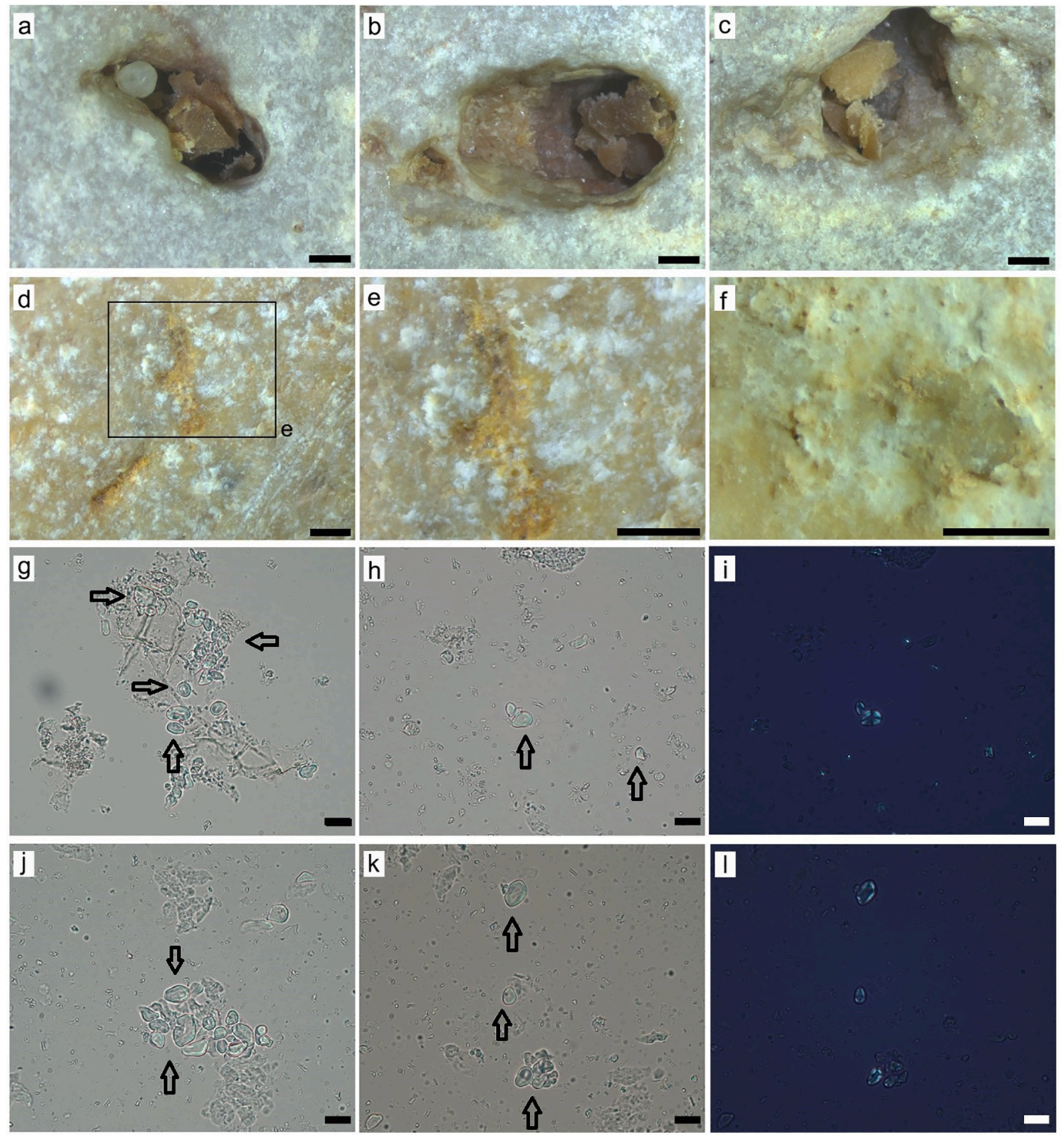

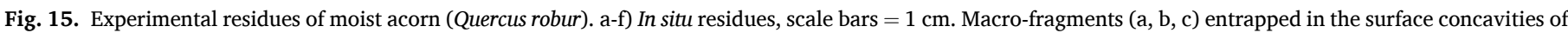
specimen 6-10 and acorn powder (d, e, f) deposited on the surface; $\mathrm{g}$-i) Starch grains observed on pipette-extracted samples under plane polarized (g, h) and crossed polarized (i) light, scale bars $=20 \mu \mathrm{m} ; \mathrm{j}-1)$ Starch grains observed on powdered samples under plane-polarized $(\mathrm{j}, \mathrm{k}$ ) and cross-polarized (l) light, scale bars $=20 \mu \mathrm{m}$. One of the micro-fragments shown on panel "c" was mechanically extracted and ground before slide preparation.

categories/properties of contact materials but not specific material in terms of species, type of bone, or plant matter. Along this line, our experiments with flint should support the identification of traces produced by contact with a hard mineral. In a similar way, our results of the dry acorn experiment should help the identification of traces generated by contact with a hard and oily seed, because at this stage of the study we do not know if the contact with other nuts or seeds, showing similar physical properties, would produce similar results. Although beyond the scope of this paper, it should be emphasized that the data presented here should be compared with manual experiments.

This work should be seen as a contribution for the field of use-wear analyses that, together with other reference collections developed by other researchers, should contribute to equip the archaeologists with essential methodological "tools" for functional interpretations of past technology.

\section{Conclusions and final remarks}

By using a multi-scale approach and combining quantitative and qualitative data, our study demonstrates the development of distinct traces at both macro and micro levels on limestone GST, and suggests diagnostic characteristics indicative of different motions and contact materials. This research more particularly provides new data and detailed descriptions regarding use-wear formation on limestone tools, here used in percussive activities for processing flint and fresh bone, and 
in grinding vegetal matter with different degrees of hardness.

Our paper presents a novel approach to the use-wear studies, highlighting the contribution of a multi-scale analytical method that integrates quantitative and qualitative approaches. One of the main original aspects of this research is the development of mechanical experiments, used here to isolate and control predefined variable and constant parameters in percussion and grinding motions usecontexts. This is regarded here as a highly informative approach to understanding use-wear formation, complementary to manual experimentation. Human movement and kinematics associated with tool use and activities are obviously complex (Bril, 1993; Bril et al., 2012) and difficult - probably impossible - to reproduce in a machine setting. Yet by enhancing parameters control, measuring the forces involved, and allowing long intensive tool use sessions, mechanized experiments can significantly contribute to our understanding of usewear formation.

This study can be seen as the first step towards the creation of an extensive use-wear reference collection, contributing to those previously developed for the study of GST in the Levant. We emphasize the importance of performing experiments with raw materials similar to those found at the archaeological sites under study. The data presented here include only GST made of limestone; however, we recognize that future experiments should explore other raw materials, since use-wear resulting from the same activities with different raw materials might be significantly different. We believe that our experimental data can serve not only as a comparative basis for the analysis GST assemblage of Nesher Ramla, but may also be relevant to other use-wear analysts working on GST made of limestone from very different geographical contexts.

\section{CRediT authorship contribution statement}

Eduardo Paixão: Writing - original draft, Software, Formal analysis, Methodology, Investigation, Formal analysis, Conceptualization. Antonella Pedergnana: Writing - original draft, Investigation, Formal analysis. João Marreiros: Writing - original draft, Software, Formal analysis, Data curation, Methodology, Supervision, Conceptualization. Laure Dubreuil: Writing - original draft, Supervision, Formal analysis, Validation, Conceptualization. Marion Prévost: Writing - review \& editing, Validation, Conceptualization. Yossi Zaidner: Writing - review \& editing, Supervision, Resources, Conceptualization. Geoff Carver: Writing - review \& editing, Software, Data curation. Walter Gneisinger: Writing - review \& editing, Methodology, Conceptualization.

\section{Acknowledgements}

This research is part of a $\mathrm{PhD}$ project (E.P.) supported within the Römisch-Germanisches Zentralmuseum - Leibniz Research Institute for Archeology by German Federal and Rhineland Palatinate funding (Sondertatbestand "Spurenlabor"). The authors would like to thank to the Irene Levi Sala Care Archaeological Foundation for an individual research grant to E.P. that supported the acquisition of limestone in Israel for the experiments (Project Title: The Ground Stone Tools of Nesher Ramla: Unrevealing Ground Stone Tools from the middle Paleolithic of Levant).

The authors also would like to thank Elaine Turner for the support during the bone acquisition for the experiments, and also to Thomas and Manuela Kurz from the "Naturteam Kurz" in Neuwied for providing the fresh bones for the experiments. Finally, the authors would like to thank the two anonymous reviewers who have contributed with many constructive comments that helped improve the paper.

\section{Appendix A. Supplementary data}

Supplementary data to this article can be found online at https://doi. org/10.1016/j.jasrep.2021.102971.

\section{References}

Adams, J., 2014. Ground stone use-wear analysis: a review of terminology and experimental methods. J. Archaeol. Sci. 48, 129-138.

Adams, J., Delgado-Raack, S., Dubreuil, L., Hamon, C., Plisson, H., \& Risch, R. 2009. Functional Analysis of Macro-Lithic Artifacts. In F. Sternke, L. Costa, \& L. Eigeland (Eds.), Non-Flint Raw Material Use in Prehistory: Old Prejudices and New Directions (pp. 43-66). Oxford: Archaeopress.

Adams, J. (1989). Methods for Improving Ground Stone Artifacts Analysis: Experiments in Mano Wear Patterns. BAR International Series, January. https://hdl.handle.net/ 2027/fulcrum.k0698910x.

Adams, J., 1988. Use-wear analyses on manos and hide-processing stones. J. Field Archaeol. https://doi.org/10.1179/009346988791974394.

Adams, J. L. (2002). Ground Stone Analysis: A technological approach. The University of Utah press.

Arroyo, A., Falótico, T., Burguet-Coca, A., Expósito, I., Quinn, P., Proffitt, T., 2021. Usewear and residue analysis of pounding tools used by wild capuchin monkeys (Sapajus libidinosus) from Serra da Capivara (Piauí, Brazil). J. Archaeol. Sci. Rep. https://doi.org/10.1016/j.jasrep.2020.102690.

Arroyo, A., de la Torre, I., 2020. Pitted stones in the Acheulean from Olduvai Gorge Beds III and IV (Tanzania): A use-wear and 3D approach. J. Hum. Evol. 145 https://doi. org/10.1016/j.jhevol.2020.102837.

Arroyo, A., Harmand, S., Roche, H., Taylor, N., 2020. Searching for hidden activities: Percussive tools from the Oldowan and Acheulean of West Turkana, Kenya (2.3-1.76 Ma). J. Archaeol. Sci. 123 https://doi.org/10.1016/j.jas.2020.105238.

De Beaune, S.A., 2004. The invention of technology. Curr. Anthropol. 45 (2), 139-162.

Been, E., Hovers, E., Ekshtain, R., Malinski-Buller, A., Agha, N., Barash, A., Mayer, D. E. B. Y., Benazzi, S., Hublin, J. J., Levin, L., Greenbaum, N., Mitki, N., Oxilia, G., Porat, N., Roskin, J., Soudack, M., Yeshurun, R., Shahack-Gross, R., Nir, N., Stahlschmidt, M., Rak, Y., Barzilai, O. 2017. The first Neanderthal remains from an open-air Middle Palaeolithic site in the Levant. Sci. Rep., 7(1). https://dx.doi.org/10.1038/s41598 -017-03025-z.

Belfer-Cohen, A., Hovers, E., 2005. The Ground Stone Assemblages of the Natufian and Neolithic Societies in the Levant - A brief review. J. Israel Prehistoric Soc. 35, 299-308.

Benito-Calvo, A., Carvalho, S., Arroyo, A., Matsuzawa, T., De LaTorre, I., 2015. First GIS analysis of modern stone tools used by Wild Chimpanzees (Pan troglodytes verus) in Bossou, Guinea, West Africa. PLoS One 10 (3). https://doi.org/10.1371/journal. pone.0121613.

Benito-Calvo, A., Crittenden, A.N., Livengood, S.V., Sánchez-Romero, L., MartínezFernández, A., de la Torre, I., Pante, M., 2018. 3D 360 ${ }^{\circ}$ surface morphometric analysis of pounding stone tools used by Hadza foragers of Tanzania: A new methodological approach for studying percussive stone artefacts. J. Archaeol. Sci. Rep. 20, 611-621. https://doi.org/10.1016/j.jasrep.2018.06.003.

Boëda, E., Bonilauri, S., Connan, J., Jarvie, D., Mercier, N., Tobey, M., Valladas, H., al Sakhel, H., \& Muhesen, S. 2008. Middle Palaeolithic bitumen use at Umm el Tlel around $70000 \mathrm{BP}$. Antiquity, 82(318), 853-861. https://dx.doi.org/10.101 7/S0003598X00097623.

Boesch, C., Boesch, H., 1984. Mental map in wild chimpanzees: An analysis of hammer transports for nut cracking. Primates. https://doi.org/10.1007/BF02382388.

Bril, B. 1993. Les Gestes de Percussion : Analyse d'un Mouvement Technique. In Savoir Faire et Pouvoir Transmettre (Ed. D. Chevallier) (pp. 61-80). Paris.

Bril, Blandine, Smaers, J., Steele, J., Rein, R., Nonaka, T., Dietrich, G., Biryukova, E., Hirata, S., \& Roux, V. 2012. Functional mastery of percussive technology in nutcracking and stone-flaking actions: Experimental comparison and implications for the evolution of the human brain. Philos. Trans. R. Soc. B Biol. Sci. https://dx.doi. org/10.1098/rstb.2011.0147.

Burrough, P.A., McDonell, R.A., 1998. Principles of Geographical Information Systems. Oxford University Press, New York.

Calandra, I., Gneisinger, W., Marreiros, J., 2020. A versatile mechanized setup for controlled experiments in archeology A versatile mechanized setup for controlled experiments in archeology. STAR Sci. Technol. Archaeol. Res. 00, 1-11. https://doi. org/10.1080/20548923.2020.1757899.

Caricola, I., Zupancich, A., Moscone, D., Mutri, G., Falcucci, A., Duches, R., Peresani, M., Cristiani, E. 2018. An integrated method for understanding the function of macrolithic tools. Use wear, 3D and spatial analyses of an Early Upper Palaeolithic assemblage from North Eastern Italy. In PLoS One (Vol. 13, Issue 12). https://dx.doi. org/10.1371/journal.pone.0207773.

Caruana, M.V., Carvalho, S., Braun, D.R., Presnyakova, D., Haslam, M., Archer, W., Bobe, R., Harris, J.W.K., 2014. Quantifying traces of tool use: A novel morphometric analysis of damage patterns on percussive tools. PLoS One 9 (11), 1-18. https://doi. org/10.1371/journal.pone.0113856.

Centi, L., Zaidner, Y. 2020. Variations in lithic artefact density as a tool for better understanding Middle Palaeolithic human behaviour: The case of Nesher Ramla (Israel). Quat. Int., November 2019, 1-15. https://dx.doi.org/10.1016/j.quaint.20 20.03.025.

Cnuts, D., Rots, V., 2017. Extracting residues from stone tools for optical analysis: towards an experiment-based protocol. Archaeol. Anthropol. Sci. 10 (7), 1717-1736. https://doi.org/10.1007/s12520-017-0484-7.

Crater Gershtein, K., Zaidner, Y., Yeshurun, R., 2020. A campsite on the open plain: Zooarchaeology of Unit III at the Middle Paleolithic site of Nesher Ramla, Israel. Quat. Int. 1-18 https://doi.org/10.1016/j.quaint.2020.01.026.

Cristiani, E., Lemorini, C., Dalmeri, G., 2012. Ground stone tool production and use in the Late Upper Palaeolithic: The evidence from Riparo Dalmeri (Venetian Prealps, Italy). J. Field Archaeol. 37 (1), 34-50. https://doi.org/10.1179/ $0093469011 \mathrm{Z} .0000000003$. 
de la Torre, I., Benito-Calvo, A., Arroyo, A., Zupancich, A., Proffitt, T., 2013. Experimental protocols for the study of battered stone anvils from Olduvai Gorge (Tanzania). J. Archaeol. Sci. 40 (1), 313-332. https://doi.org/10.1016/j. jas.2012.08.007.

Dubreuil, L. 2002. Etude Fonctionnelle des Outils de Broyage Natoufiens: Nouvelles Perspectives sur l'Emergence de l'Agriculture au Proche-Orient. Université de Bordeaux.

Dubreuil, L., 2004. Long-term trends in Natufian subsistence: A use-wear analysis of ground stone tools. J. Archaeol. Sci. https://doi.org/10.1016/j.jas.2004.04.003.

Dubreuil, Laure, Grosman, Leore, 2009. Ochre and hide-working at a Natufian burial place. Antiquity. https://doi.org/10.1017/S0003598X00099269.

Dubreuil, L., Savage, D., 2014. Ground stones: a synthesis of the use-wear approach. J. Archaeol. Sci. 48, 139-153. https://doi.org/10.1016/j.jas.2013.06.023.

Dubreuil, L., Savage, D., Delgado-Raack, S., Plisson, H., Stephenson, B., de la Torre, I. 2015. Current Analytical Frameworks for Studies of Use-Wear on Ground Stone Tools. In J.M. Marreiros, J.F. Gibaja Bao, N. Ferreira Bicho (Eds.), Use-Wear and Residue Analysis in Archaeology (pp. 101-158). Springer International Publishing. https://link.springer.com/10.1007/978-3-319-08257-8.

Ekshtain, R., Malinsky-Buller, A., Greenbaum, N., Mitki, N., Stahlschmidt, M. C., Shahack-Gross, R., Nir, N., Porat, N., Bar-Yosef Mayer, D. E., Yeshurun, R., Been, E., Rak, Y., Agha, N., Brailovsky, L., Krakovsky, M., Spivak, P., Ullman, M., Vered, A., Barzilai, O., \& Hovers, E. (2019). Persistent Neanderthal occupation of the open-air site of 'Ein Qashish, Israel. In PLoS One (Vol. 14, Issue 6). https://dx.doi.org/ 10.1371/journal.pone.0215668.

Fullagar, R. 2014. Residues and Usewear. In A. Paterson (Ed.), Archaeology in Practice: A Student Guide to Archaeological Analyses. (pp. 232-263). Malden: Blackwell Publishing.

Fullagar, R., Liu, L., Bestel, S., Jones, D., Ge, W., Wilson, A., Zhai, S., 2012. Stone tool-use experiments to determine the function of grinding stones and denticulate sickles. Bull. Indo-Pacific Prehistory Assoc. 32 (1), 29-44. https://doi.org/10.7152/bippa. v32i0.12931.

Gilead, I., Grigson, C., 1984. Far'ah II A Middle Palaeolithic Open-Air Site in the Northern Negev, Israel. Grants Register 2020 (50), 71-97. https://doi.org/10.1057/ 978-1-349-95943-3_698.

Gismondi, A., D’Agostino, A., Canuti, L., Di Marco, G., Basoli, F., Canini, A., 2019. Starch granules: A data collection of 40 food species. Plant Biosyst. https://doi.org/ 10.1080/11263504.2018.1473523.

Goder-Goldberger, M., Crouvi, O., Caracuta, V., Kolska Horwitz, L., Neumann, F.H., Porat, N., Scott, L., Shavit, R., Jacoby-Glass, Y., Zilberman, T., Boaretto, E., 2020. The Middle to Upper Paleolithic transition in the southern Levant: New insights from the late Middle Paleolithic site of Far'ah II, Israel. Quat. Sci. Rev. 237 https://doi. org/10.1016/j.quascirev.2020.106304.

Goren-Inbar, N. 1990. The Lithic Assemblages. In Quneitra: A Mousterian site on the Golan Heights (pp. 61-149). The Hebrew University of Jerusalem.

Goren-Inbar, N., Sharon, G., Alperson-Afil, N., Herzlinger, G., 2015. A new type of anvil in the acheulian of gesher benot ya'aqov, Israel. Philos. Trans. R. Soc. B Biol. Sci. 370 (1682) https://doi.org/10.1098/rstb.2014.0353.

Goren-Inbar, N., Sharon, G., Melamed, Y., Kislev, M., 2002. Nuts, nut cracking, and pitted stones at Gesher Benot Ya'aqov, Israel. Proc. Natl. Acad. Sci. U.S.A. 99 (4), 2455-2460. https://doi.org/10.1073/pnas.032570499.

Griggo, C., Boëda, É., Bonilauri, S., Al Sakhel, H., Emery-Barbier, A., Courty, M. 2011. A Mousterian Dromedary Hunting Camp: Level VI1aO at Umm el Tlel (El Kowm, Central Syria). In F. Bon, S. Costamagno, N. Valdeyron (Eds.), Hunting Camps in Prehistory. Current Archaeological Approaches. (pp. 103-129). P@lethnologie association.

Hayes, E. 2015. What was ground? A functional analysis of grinding stones from Madjedbebe and Lake Mungo, Australia. University of Wollongong.

Hayes, E., Pardoe, C., Fullagar, R., 2018. Sandstone grinding/pounding tools: Use-trace reference libraries and Australian archaeological applications. J. Archaeol. Sci.: Rep. 20, 97-114. https://doi.org/10.1016/j.jasrep.2018.04.021.

Hovers, E., Oron, M., Yeshurun, R., 2008. 'Ein Qashish - A new open-air Middle Paleolithic Site in Northern Israel. J. Israel Prehistoric Soc. 38, 7-40.

Iovita, R., Schönekeß, H., Gaudzinski-Windheuser, S., Jäger, F., 2014. Projectile impact fractures and launching mechanisms: Results of a controlled ballistic experiment using replica Levallois points. J. Archaeol. Sci. 48 (1), 73-83. https://doi.org/ 10.1016/j.jas.2013.01.031

ISO. 2005. Geometrical Product Specifications (GPS) - Surface texture: Profile method — Terms, definitions and surface texture parameters (Corr 2). 2005, 1997-1998. 10.3403/02031657.

International Organization for Standardization (2012) ISO 25178-2 - Geometrical product specifications (GPS) - Surface texture: Areal - Part 2: Terms, definitions and surface texture parameter.

Li, W., Tsoraki, C., Yang, Y., Xin, Y., van Gijn, A., 2020. Plant foods and different uses of grinding tools at the Neolithic Site of Tanghu in Central China. Lithic Technol. https://doi.org/10.1080/01977261.2020.1755789.

Lippi, M.M., 2018. The contribution of starch grain and phytolith analyses in reconstructing ancient diets. Flora Mediterranea 28. https://doi.org/10.7320/ FlMedit28.287.
Lippi, M.M., Foggi, B., Aranguren, B., Ronchitelli, A., Revedin, A., 2015. Multistep food plant processing at Grotta Paglicci (Southern Italy) around 32,600 cal B.P. Proc. Natl. Acad. Sci. U.S.A. https://doi.org/10.1073/pnas.1505213112.

Liu, L., Field, J., Fullagar, R., Bestel, S., Chen, X., Ma, X., 2010. What did grinding stones grind? New light on Early Neolithic subsistence economy in the Middle Yellow River Valley, China. Antiquity 84 (325), 816-833. https://doi.org/10.1017/ S0003598X00100249.

Malinsky-Buller, A., Ekshtain, R., Hovers, E., 2014. Organization of lithic technology at 'Ein Qashish, a late Middle Paleolithic open-air site in Israel. Quat. Int. 331, 234-247. https://doi.org/10.1016/j.quaint.2013.05.004.

Marreiros, J., Calandra, I., Gneisinger, W., Paixão, E., Pedergnana, A., Schunk, L., 2020. Rethinking use-wear analysis and experimentation as applied to the study of Past Hominin Tool Use. J. Paleolithic Archaeol. https://doi.org/10.1007/s41982-02000058-1.

Marreiros, J., Pereira, T., Iovita, R., 2020. Controlled experiments in lithic technology and function. Archaeol. Anthropol. Sci. 12 (6), 110. https://doi.org/10.1007/ s12520-020-01059-5.

Oron, M., Goren-Inbar, N., 2014. Mousterian intra-site spatial patterning at quneitra, golan heights. Quat. Int. 331, 186-202. https://doi.org/10.1016/j. quaint.2013.04.013.

Pereira, T., Marreiros, J., Paixao, E., Martins, R., 2017. Mechanical experiments to test quartzite vs chert edge reduction. The Exploitation of Raw Materials in Prehistory: Sourcing. Process. Distribution 613-626.

Pop, E., Charalampopoulos, D., Arps, C.S., Verbaas, A., Roebroeks, W., GaudzinskiWindheuser, S., Langejans, G., 2018. Middle Palaeolithic percussive tools from the Last Interglacial Site Neumark-Nord 2/2 (Germany) and the visibility of such tools in the archaeological record. J. Paleolithic Archaeol. 1 (2), 81-106. https://doi.org/ 10.1007/s41982-018-0008-8.

Prévost, M., Zaidner, Y. 2020. New insights into early MIS 5 lithic technological behavior in the Levant: Nesher Ramla, Israel as a case study. PLoS One, 15(4). https://dx.doi. org/10.1371/journal.pone.0231109.

Procopiou, H. 2004. Le broyage des matières minérales: l'apport de la tribologie à l'identification de la transformation des matières minérales. Dossiers d'Archéologie, La Tribologie, 58-61.

Procopiou, H., Jautée, E., Vargiolu, R., Zahouni, H. 1998. Petrographic and Use-Wear Analysis of a Quern from Syvritos Kephala. In F. Facchini, A. Palma Di Cesnola, M. Piperno, \& C. Peretto (Eds.), Analyse Fonctionnelle Des Pièces Lithiques : Situation Actuelle de La Recherche (pp. 1183-1192). A.B.A.C.O.

Riley, S.J., DeGloria, S.D., Elliot, R., 1999. A Terrain Ruggedness index that quantifies topographic heterogeneity. Intermountain J. Science 5, 23-27.

Rosenberg, D., Nadel, D., 2017. The significance of the morphometric and contextual variation in stone hewn mortars during the Natufian-PPNA transition in the southern Levant. Quat. Int. 439, 83-93. https://doi.org/10.1016/j.quaint.2016.11.023.

Schulz, E., Calandra, I., Kaiser, T.M., 2013. Feeding ecology and chewing mechanics in hoofed mammals: 3D tribology of enamel wear. Wear 300 (1-2), 169-179.

Semenov, S. 1964. Prehistoric technology: An experimental study of the oldest tools and arte- facts from traces of manufacture and wear. Cory, Adams e Mackay.

Torre, I. de la, Mora, R. 2010. A technological analysis of non-flaked stone tools in Olduvai Beds I \& II. Stressing the relevance of percussion activities in the African Lower Pleistocene. SAMRA, Numéro spécial, 13-34. https://journals.openedition. org/paleo/1877.

Torrence, R., \& Barton, H. (2016). Ancient Starch Research. In Ancient Starch Research. Routledge. 10.4324/9781315434896.

Valamoti, S., Chondrou, D., Papadopoulou, L. 2013. Plant food processing and ground stone equipment in prehistoric Greece: An experimental investigation using seeds of einkorn and grass-pea. In P. C. Anderson, C. Cheval, A. Durand (Eds.), Regards croisés sur les outils liés au travail des végétaux. An interdisciplinary focus on plantworking tools, Juan-les-Pins: APDCA, pp. 169-187.

Whiten, A., Horner, V., De Waal, F.B.M., 2005. Conformity to cultural norms of tool use in chimpanzees. Nature. https://doi.org/10.1038/nature04047.

Wright, K.I., 1994. Ground-stone tools and hunter-gatherer subsistence in Southwest Asia: Implications for the transition to farming. Am. Antiq. https://doi.org/10.2307/ 281929.

Zaidner, Y., Centi, L., Prevost, M., Shemer, M., Varoner, O. 2018. An Open-Air Site at Nesher Ramla, Israel, and New Insights into Levantine Middle Paleolithic Technology and Site Use. In Y. Nishiaki \& T. Akazawa (Eds.), The Middle and Upper Paleolithic Archeology of the Levant and Beyond. Singapore: Springer, 11-33. https://dx.doi.org/10.1007/978-981-10-6826-32.

Zaidner, Y., Frumkin, A., Porat, N., Tsatskin, A., Yeshurun, R., Weissbrod, L., 2014. A series of Mousterian occupations in a new type of site: The Nesher Ramla karst depression, Israel. J. Hum. Evol. 66, 1-17. https://doi.org/10.1016/j ihevol.2013.06.005.

Zupancich, A., Mutri, G., Caricola, I., Carra, M.L., Radini, A., Cristiani, E., 2019. The application of 3D modeling and spatial analysis in the study of groundstones used in wild plants processing. Archaeol. Anthropol. Sci. 11 (9), 4801-4827. https://doi. org/10.1007/s12520-019-00824-5. 